\title{
El Niño-Southern Oscillation signals in sea level, surface mass redistribution, and degree-two geoid coefficients
}

Felix W. Landerer, ${ }^{1,2,3}$ Johann H. Jungclaus, ${ }^{1}$ and Jochem Marotzke ${ }^{1}$
Received 8 February 2008; revised 28 April 2008; accepted 20 May 2008; published 8 August 2008.

[1] We use a coupled Earth system model to simulate and quantify the impact of the El Niño-Southern Oscillation (ENSO) on monthly to interannual variations of steric and eustatic global mean sea level (GMSL), surface mass loading, and on the corresponding degree-two geoid coefficients $\left(C_{21}, S_{21}\right.$, and $\left.C_{20}\right)$. GMSL is dominated by eustatic variations on monthly to interannual timescales, but less than $10 \%$ of the eustatic variance is related to ENSO. In contrast, steric GMSL correlates linearly in phase with ENSO with an explained variance of nearly $46 \%$. Together these results imply that total GMSL

variations are only weakly correlated with ENSO. Despite this small correlation, we find a distinct ENSO pattern of sizable surface mass load anomalies. Over the continents, this pattern is similar to typical ENSO-related precipitation anomalies. Over the oceans, the pattern features a global, albeit weaker, response, with generally increased loading in the Arctic and Pacific oceans, and decreased loading in the Atlantic and Indian oceans. These surface loading anomalies lead to statistically significant ENSO-related variations in the $S_{21}$ and $C_{20}$ geoid coefficients, but not in $C_{21}$. In analyzing the individual subsystem contributions, we find that $S_{21}$ is influenced by both ocean mass redistribution and soil moisture loading, whereas $C_{20}$ is mainly influenced by soil moisture loading. Our results highlight the importance of high-amplitude regional loading anomalies that integrate to low-degree geoid anomalies.

Citation: Landerer, F. W., J. H. Jungclaus, and J. Marotzke (2008), El Niño-Southern Oscillation signals in sea level, surface mass redistribution, and degree-two geoid coefficients, J. Geophys. Res., 113, C08014, doi:10.1029/2008JC004767.

\section{Introduction}

[2] Global mean sea level (GMSL) is greatly influenced by the variable water exchange between the oceans, atmosphere and continents. This mass exchange is largely modulated by the global hydrological cycle via precipitation, evapotranspiration and river runoff. In the atmosphere, water is mainly stored in the form of water vapor, the holding capacity being mainly a function of air temperature [e.g., Gill, 1982]. On the continents, water can be stored in various reservoirs, e.g., in rivers and lakes, in the ground and soil, or as snow and ice [Cazenave et al., 2000]. The exchange of water between the different subsystems not only affects GMSL, but it also induces variations in Earth's geopotential field. The link between GMSL, surface mass redistribution, and geodetic variations is not an obvious one, but in particular degree-two coefficients of Earth's gravity field, which are related to Earth rotation parameters, can provide an independent constraint on GMSL variations

\footnotetext{
${ }^{1}$ Max Planck Institute for Meteorology, Hamburg, Germany.

${ }^{2}$ International Max Planck Research School on Earth System Modelling, Hamburg, Germany.

${ }^{3}$ Jet Propulsion Laboratory, California Institute of Technology, Pasadena, California, USA.
}

Copyright 2008 by the American Geophysical Union. 0148-0227/08/2008JC004767
[Munk, 2002]. As these geodetic variables represent an integral measure of all relevant geophysical processes within and above the solid Earth, it is necessary to resolve this ambiguity by explicitly evaluating plausible mechanisms of mass redistribution in the Earth system.

[3] Seasonal freshwater flux imbalances between the oceans, continents and atmosphere, which result in equivalent sea level variations, are relatively well quantified [e.g., Chen et al., 1998; Cazenave et al., 2000; Willis et al., 2008]. On interannual timescales, however, much less is known about the mechanisms and magnitudes of natural sea level and water storage variability. Quantifying these effects is essential in order to infer accurate rates of longer-term sea level trends, in particular those related to global warming [Nerem et al., 1999; Church et al., 2001]. A dominant mode of interannual climate variability is the El Niño-Southern Oscillation (ENSO) [e.g., McPhaden et al., 2006]. ENSO involves large-scale reorganizations of the atmospheric and oceanic circulation that originate in the equatorial Pacific, leading to temperature and precipitation anomalies extending across the entire globe [e.g., Soden, 2000; Trenberth and Caron, 2000; Trenberth et al., 2005]. If these reorganizations lead to freshwater flux imbalances, ENSO will also imply mass-related GMSL changes. Moreover, ENSO is associated with significant ocean temperature changes, which result in density-related GMSL anomalies. For the 
remainder of the paper, we follow typical standard convention and distinguish between steric (density-related) and eustatic (mass-related) sea level changes [e.g., Cazenave and Nerem, 2004]. A weak tendency of positive correlations between ENSO and GMSL over the last 50 years was reported by Chambers et al. [2002], but the magnitude of GMSL changes appeared not to be linearly related to ENSO strengths. One of the strongest and particularly well observed ENSO events occurred in 1997/1998. This prominent event was marked by a large positive GMSL anomaly. On the basis of altimetry observations and model simulations, Nerem et al. [1999] concluded that this anomaly was mainly of steric origin. Willis et al. [2004], on the other hand, reported in their objective analysis of oceanic hydrographic profile observations that large amounts of heat were redistributed within the ocean during the 1997/1998 El Niño, but since the total global ocean heat content was not changed, they concluded that the observed GMSL anomaly was largely eustatic. However, no direct observations of the hydrologic contribution to this GMSL anomaly exist. Regardless of its eustatic or steric nature, trend estimates of sea level rise can be significantly affected by ENSO-related sea level anomalies [Nerem et al., 1999]. Coinciding with the GMSL anomaly during the ENSO event in 1997/1998, a prominent anomaly in the Earth's geodetic oblateness $\left(C_{20}\right)$ was also observed. This anomaly was consistent with a mass transport from high to low latitudes [Cox and Chao, 2002], and Dickey et al. [2002] argued that a substantial part of the $C_{20}$ anomaly could be attributed to subpolar glacial melting and to dynamic ocean mass redistribution. While the latter process does not change GMSL, the former should lead to an increase of GMSL. Others [e.g., Cox and Chao, 2002] have argued against ice sheet changes as a major source for the observed $1997 / 1998 C_{20}$ anomaly, because the implied GMSL signal would have been larger than observed. Subsequently, Cheng and Tapley [2004] argued that changes in terrestrial water storage contributed significantly to the anomalous $C_{20}$ event in 1997/1998. In any case, the dynamic links between such mass shifts, GMSL, and large-scale climate modes, such as ENSO, remain to be established and quantified.

[4] In what follows, we investigate two issues that are still unresolved in terms of sea level change and large-scale hydrological mass redistribution: First, does ENSO systematically change steric and eustatic GMSL, and how is the eustatic sea level anomaly balanced? Second, to what extent are interannual anomalies in the degree-two geopotential coefficients explained by ENSO-related surface mass redistributions, and what are the geographical patterns and contributions of the individual storage reservoirs that lead to these anomalies? We explore these two issues in a novel approach by using an unconstrained state-of-the-art Earth system model. Our approach aims at understanding typical magnitudes and mechanisms of these signals, rather than comparing the results directly to observations. The main challenge in observing and simulating the water cycling between the oceans, atmosphere and continents is the closure of the total water budget. Coupled global atmosphere-ocean general circulation models have been extended to include land-surface and river routing schemes, which allow for the storage of water in the soil and as snow. Although many of the governing processes of the hydrological cycle, especially on land, are still poorly understood (and therefore highly parameterized in their numerical representation), these models offer the advantage of consistent fresh water fluxes between the hydrological reservoirs without the need of artificial flux adjustments. Additionally, the models feature global coverage, which is essential to capture the total Earth system response in light of large-scale ENSO teleconnections [Hughes and Stepanov, 2004; Trenberth et al., 1998].

[5] This paper is organized as follows: in section 2, we briefly review the model setup and methods used in the analysis; in section 3 , we present our detailed results; in section 4, we summarize our results and discuss their implications; in section 5, we list our final conclusions.

\section{Model and Methods \\ 2.1. ECHAM5/MPI-OM Model}

[6] We use monthly data from 200 years of a climate simulation computed with the coupled ECHAM5/MPI-OM atmosphere-ocean general circulation model (see special section "Climate Models at the Max Planck Institute for Meteorology" in Journal of Climate, 19(16), 3792-3987, 2006 for ECHAM5/MPI-OM details), which also served as the unperturbed reference climate for the projections included in IPCC 4th assessment report [Meehl et al., 2007]. No anthropogenic or volcanic forcing is included; the concentrations of well-mixed greenhouse gases are set to preindustrial values (year 1860). The ocean component MPI-OM [Marsland et al., 2003] has a vertical resolution of 40 levels, 20 of which are distributed over the upper $700 \mathrm{~m}$; partial grid cells resolve the bottom topography. Horizontally, the resolution varies between $12 \mathrm{~km}$ and $180 \mathrm{~km}$. MPI-OM is coupled to the ECHAM5 atmosphere model [Roeckner et al., 2003] at T63 horizontal resolution $\left(1.875^{\circ} \times 1.875^{\circ}\right)$ with 31 vertical levels; the coupling of the atmosphere to the ocean requires no flux adjustments. However, we do need to subtract a drift of $-0.142 \mathrm{~mm} / \mathrm{a}$ (where a is years) of the global mean fresh water flux over the ocean, which would otherwise lead to an unphysical mass loss in the ocean. This drift correction is small and does not influence any of the results presented here. A dynamic/thermodynamic sea ice model with viscous-plastic rheology is embedded in MPIOM. More details on the ocean model formulation is given by Marsland et al. [2003] and Jungclaus et al. [2006]. Note that the ocean component has not yet reached its equilibrium state in this simulation, which is largely related to insufficient Antarctic Bottom Water formation [Jungclaus et al., 2006; Landerer et al., 2007a]. This results in a slow warming of intermediate and deep waters (about $2.6 \times$ $10^{21} \mathrm{~J} / \mathrm{a}$ or steric sea level drift of $0.4 \mathrm{~mm} / \mathrm{a}$ ). As the trend weakens over time, we apply a quadratic drift correction to the ocean heat content and steric sea level, rather than a simple linear fit. On the continents, surface runoff and drainage are calculated by a runoff scheme [Dümenil and Todini, 1992], and fed into a hydrological discharge (HD) model [Hagemann and Dümenil, 1998], with the limitation that growing and melting of land ice is not considered, effectively excluding cryospheric variability in the simulations. Over the ice sheets, precipitation (minus evaporation) is routed to the nearest ocean grid point as runoff. Water on the continents can be stored as snow or in the soil; the maximum soil moisture bucket depth extends to about $2 \mathrm{~m}$, 


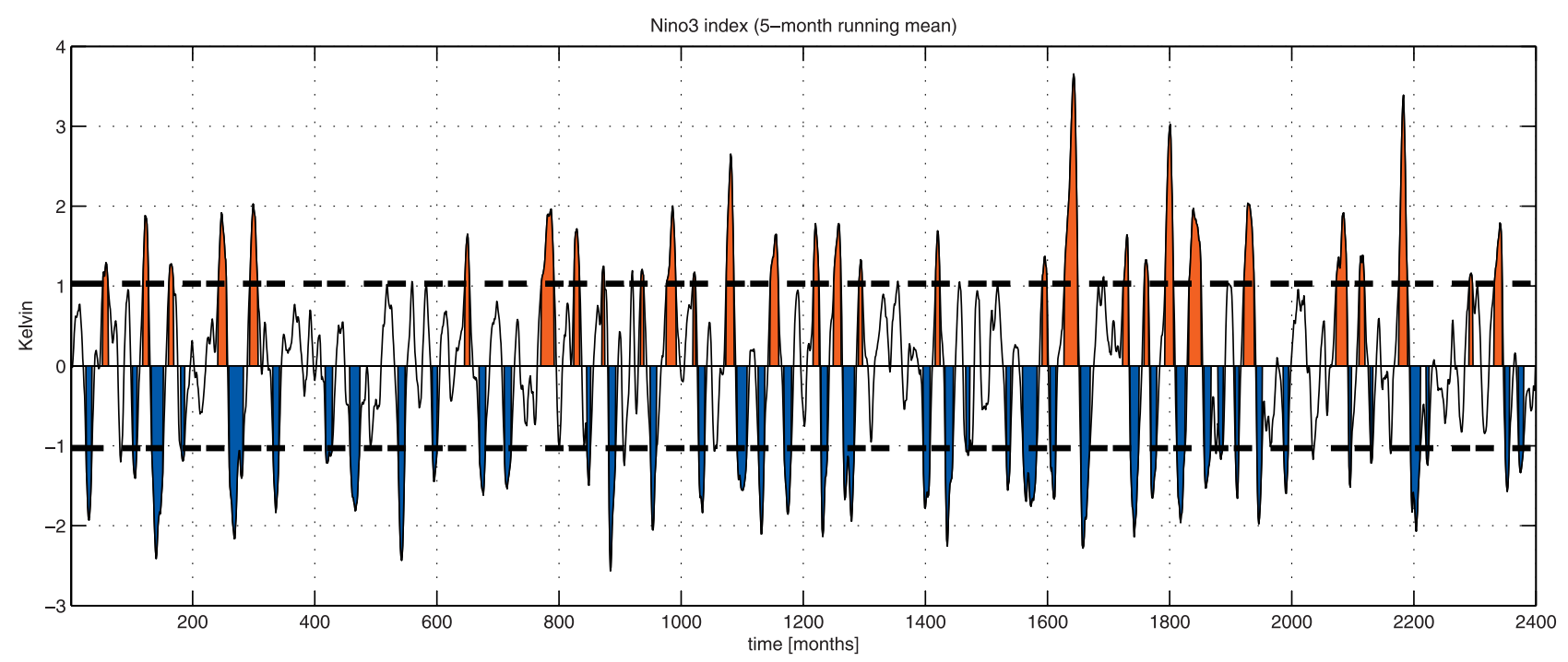

Figure 1. Simulated Nino3-SST index, with a 5-month running mean applied. The dashed line is the $1 \sigma$ standard deviation; El Niño (red) and La Niña (blue) events are defined as periods where the index exceeds $1 \sigma$ for at least 6 consecutive months.

and varies according to land surface parameters [Hagemann, 2002].

[7] The spatial structure of ENSO-related interannual sea surface temperature (SST) anomalies in the tropical Pacific is well simulated. However, the magnitude of the variability is overestimated by a factor of up to 1.4 [Guilyardi, 2006; Jungclaus et al., 2006]. Likewise, the precipitation response to ENSO events captures most aspects of the observed distribution, but the simulated amplitude is somewhat too large [Hagemann et al., 2006]. For the following regression analysis, we use the Nino3 index, which is defined as monthly SST anomalies averaged over the region of $5^{\circ} \mathrm{S}-$ $5^{\circ} \mathrm{N}$ and $150^{\circ} \mathrm{W}-90^{\circ} \mathrm{W}$ [Trenberth, 1997]. We identify an El Niño (positive values) or La Niña (negative values) event if the 5-month running average of the index exceeds one standard deviation for at least 6 consecutive months (Figure 1). A 5-month running average is used to smooth out variations in SST not associated with ENSO. In order to extract the ENSO contribution in the signals of interest, we project them onto the $1 \sigma$-normalized Nino3 index using a lagged linear least squares regression (see section 2.3 for details); positive lags mean that the Nino3 index leads the variable of interest.

[8] Mass conservation of fresh water requires that the sum of fresh water storage terms for the ocean $\left(M_{\text {oce }}\right)$, atmosphere $\left(M_{\text {atmo }}\right)$ and continents $\left(M_{\text {terra }}\right)$ does not change over time. We compute $M_{\text {oce }}$ by integrating the net global mean ocean freshwater flux. The atmospheric water content, $M_{\text {atmo }}$, is given prognostically by ECHAM5. Here, we use only the vertically integrated water vapor, because the contributions from cloud water and cloud ice to the water mass budget in ECHAM5 are smaller by a factor of about 1000 (not shown). The change in terrestrial water storage (TWS), $\Delta M_{\text {terra }}$, is equal to $(P-E-R) \Delta t$, where $P$ is precipitation, $E$ is evaporation, $R$ is runoff over land and $\Delta t$ is a time step. Here, we diagnose $\Delta M_{\text {terra }}$ from the anomalies of the water stored as soil moisture and snow in our coupled model. However, some surface water directly enters into the lateral flow scheme of the HD model. Also, the HD model temporarily stores runoff and drainage fluxes in buffer reservoirs that account for the residence times of water in the different flow processes within an HD model grid box, and between grid boxes (S. Hagemann, 2007, personal communication). The inter-grid box flow may also be interpreted as the water stored in the river network. As the buffer reservoir terms are not saved to disk in the standard ECHAM5 configuration, we correct for this runoff bias by computing the balance between eustatic sea level, atmospheric water storage, and water storage in the soil and snow on the continents; the amplitude and relevance of the runoff bias is discussed in section 3.1.

[9] In this paper, we distinguish between variations in total ocean mass (or, equivalently, eustatic sea level) and variations in local ocean bottom pressure. The latter are associated with dynamic ocean mass redistribution, where the global ocean mass remains constant. As will become clear shortly, ocean mass load is synonymous to ocean bottom pressure, the two being related linearly. Some implicit model assumptions warrant a detailed description of the calculation of ocean bottom pressure; in our derivation, we follow Ponte [1999]. The integration of the hydrostatic equation over the whole water column gives

$$
p_{b}=g \int_{-H}^{\eta} \rho d z+p_{a} \approx g \rho_{0} \eta+g \int_{-H}^{0} \rho d z+p_{a},
$$

where $g$ is the mean surface gravitational acceleration, $p_{a}$ is the surface atmospheric pressure, $\rho$ is the density, $\rho_{0}$ is the mean density of sea water, and $\eta$ the sea level above a reference level. Under the inverted barometer (IB) assumption, which holds on time scales longer than a few days [Ponte et al., 1991; Wunsch and Stammer, 1997], it can be shown that $\eta=\eta_{I B}+\eta_{d y n}$, where $\eta_{d y n}$ is a dynamic signal 
related to pressure, wind, or any other forcing. The IB term is defined as

$$
\eta_{\mathrm{IB}}=\frac{1}{g \rho_{0}}\left(\overline{p_{a}}-p_{a}\right),
$$

where $p_{a}$ is the area averaged pressure over the global oceans and IB is inverted barometer. Equation (1) then reduces to

$$
p_{b}=g \rho_{0} \eta_{d y n}+g \int_{-H}^{0} \rho d z+\overline{p_{a}} .
$$

The term $\eta_{d y n}$ in MPI-OM is calculated from the vertically integrated continuity equation under the Boussinesq approximation. While this formulation yields correct relative horizontal sea level gradients, volume rather than mass is conserved in the ocean [Gill, 1982]. Therefore, two spatially uniform, but time-varying correction terms must be applied to the calculated sea level to make up for missing physics in the model: one is the "steric correction" $\left(\overline{\eta_{s}^{\prime}}\right)$, which accounts for any net expansion or contraction of the global ocean due to changes in the density structure, and the second correction is "eustatic" $\left(\overline{\eta_{Q}^{\prime}}\right)$ and accounts for global ocean mass (or eustatic sea level) changes by adding a uniform layer of water over the oceans determined from the global integral of fresh water flux over time [Greatbatch, 1994]. Since both corrections are spatially uniform, they are not relevant dynamically. Introducing the correction terms into equation (2) then yields

$$
\frac{p_{b}^{\prime}}{g \rho_{0}}=\eta_{d y n}^{\prime}-\eta_{s}^{\prime}+\overline{\eta_{s}^{\prime}}+\overline{\eta_{a}^{\prime}}+\overline{\eta_{Q}^{\prime}}
$$

where the prime indicates the anomaly relative to a time mean or an unperturbed state, and bottom pressure is normalized to units of equivalent water column height (which we use throughout the rest of this paper). The term $\eta_{s}^{\prime}=\rho_{0}^{-1} \int \rho^{\prime} d z$ is the steric height anomaly, $\overline{\eta_{a}^{\prime}}$ is the bottom pressure contribution due to changes of the total atmospheric mass over the oceans (subsequently referred to as atmospheric ocean loading). Therefore, in a stratified ocean, sea level and bottom pressure can be very different [Condi and Wunsch, 2004]. Generally, steric effects become more important at longer periods and toward the equator, indicating that oceanic variability in these regions is more baroclinic, whereas the shallow ocean is characterized by barotropic variability [Vinogradova et al., 2007]. Consequently, the term $\eta_{d y n}^{\prime}-\eta_{s}^{\prime}+\overline{\eta_{s}^{\prime}}$ represents bottom pressure variations due to dynamic ocean mass redistribution at constant global ocean mass, which we will refer to as dynamic bottom pressure in this paper. The seasonal dynamic bottom pressure variability in MPI-OM agrees well with that described by Condi and Wunsch [2004]: high variability is found in Northwest Pacific, Southern Pacific, high-latitude Atlantic oceans, and shallow regions in general (not shown).

\subsection{Geopotential and Stokes Coefficients}

[10] Earth's geopotential field $U$ can be expanded into spherical harmonics, the so-called Stokes coefficients, which are related to Earth's density distribution [Heiskanen and Moritz, 1967]. In the special case of mass load variations, $\Delta q$, at or near Earth's surface (thin shell approximation), the Stokes coefficients $C_{l m}$ and $S_{l m}$ of degree $l$ and order $m$ are given by [Heiskanen and Moritz, 1967; Eubanks, 1993; Wahr et al., 1998]

$$
\left(\begin{array}{c}
\Delta C_{l m} \\
\Delta S_{l m}
\end{array}\right)=\frac{\left(1+k_{l}\right)}{(2 l+1) M} \int_{S} \Delta q \bar{P}_{l m}(\sin \phi)\left(\begin{array}{c}
\cos (m \lambda) \\
\sin !(m \lambda)
\end{array}\right) d S,
$$

where $\Delta q=p_{b}{ }^{\prime}(\lambda, \phi) g^{-1}, S$ is Earth's surface area, $\phi$ is latitude, $\lambda$ longitude, $M$ Earth's mass, $\bar{P}_{l m}(\sin \phi)$ are the fully normalized associated Legendre polynomials, and $k_{l}$ is the Love number, taken here as $k_{2}=-0.301$ [Chen et al., 2005]. The Love number takes into account the yielding of the solid Earth to the surface mass load changes, assuming an elastic load response [Wahr et al., 1998]. In the case of a spatially uniform mass load change, $\Delta q_{\text {uni }}$, over the oceans (either through $\overline{\eta_{a}^{\prime}}$ or $\overline{\eta_{O}^{\prime}}$, see equation (3)), the associated geopotential degree-two coefficient anomalies are given by

$$
\left.\begin{array}{l}
\Delta C_{21} \\
\Delta S_{21} \\
\Delta C_{20}
\end{array}\right\}=\Delta q_{u n i} \times 1.0^{-10} \times\left\{\begin{array}{l}
4.76 \\
7.62 \\
7.22
\end{array}\right.
$$

where $\Delta q_{u n i}=\overline{\eta^{\prime}} \rho_{0}$. Therefore, the relative contribution of a eustatic GMSL or a global mean IB anomaly is about $40 \%$ larger in $S_{21}$ relative to $C_{21}$. Note that the degree-two Stokes coefficients are directly proportional to Earth rotational excitations that are induced by surface mass load variations [Barnes et al., 1983; Chen et al., 2005]. Also note that sometimes the nonnormalized zonal coefficients $J_{l}$ are used instead of $C_{l 0}$, where $C_{l 0}=-J_{l} / \sqrt{(2 l+1)}$. Measurements of time varying gravity aim at the inversion of equation (4) to determine the surface mass load distribution $\Delta q(\phi, \lambda, t)$, but this inversion cannot uniquely determine the cause of gravity anomalies. Nonetheless, the Stokes coefficients place an integral constraint on possible mass load distributions, which must then be tested for consistency with independent observations or models.

\subsection{Linear Regression}

[11] We use a linear least squares approach to project the monthly water storage and degree-two coefficient anomalies on the Nino3 index. The Nino3 index is normalized by its standard deviation, denoted $\sigma_{N 3}$, and the regression coefficients are calculated for lags up to \pm 60 months; positive lags mean that the Nino3 index leads. In order to remove decadal and longer-period variability that is not related to ENSO, we apply a high-pass Butterworth filter with a cutoff period of about 11 years to all time series prior to the regression analysis. The significance (set here to 95\%) of the regression is computed from the regression model's $\mathrm{F}$ statistic by testing against the null hypothesis that there is no regression relationship between the variables [von Storch and Zwiers, 1999]. This estimate depends on the degrees of freedom in the time series, which for independent samples is equivalent to $N-2$, where $N$ is the total sample size. However, not all samples in the present analysis are truly independent. Intrinsic low-frequency variability or low-pass filtering (e.g., applying a running mean, as used here) 

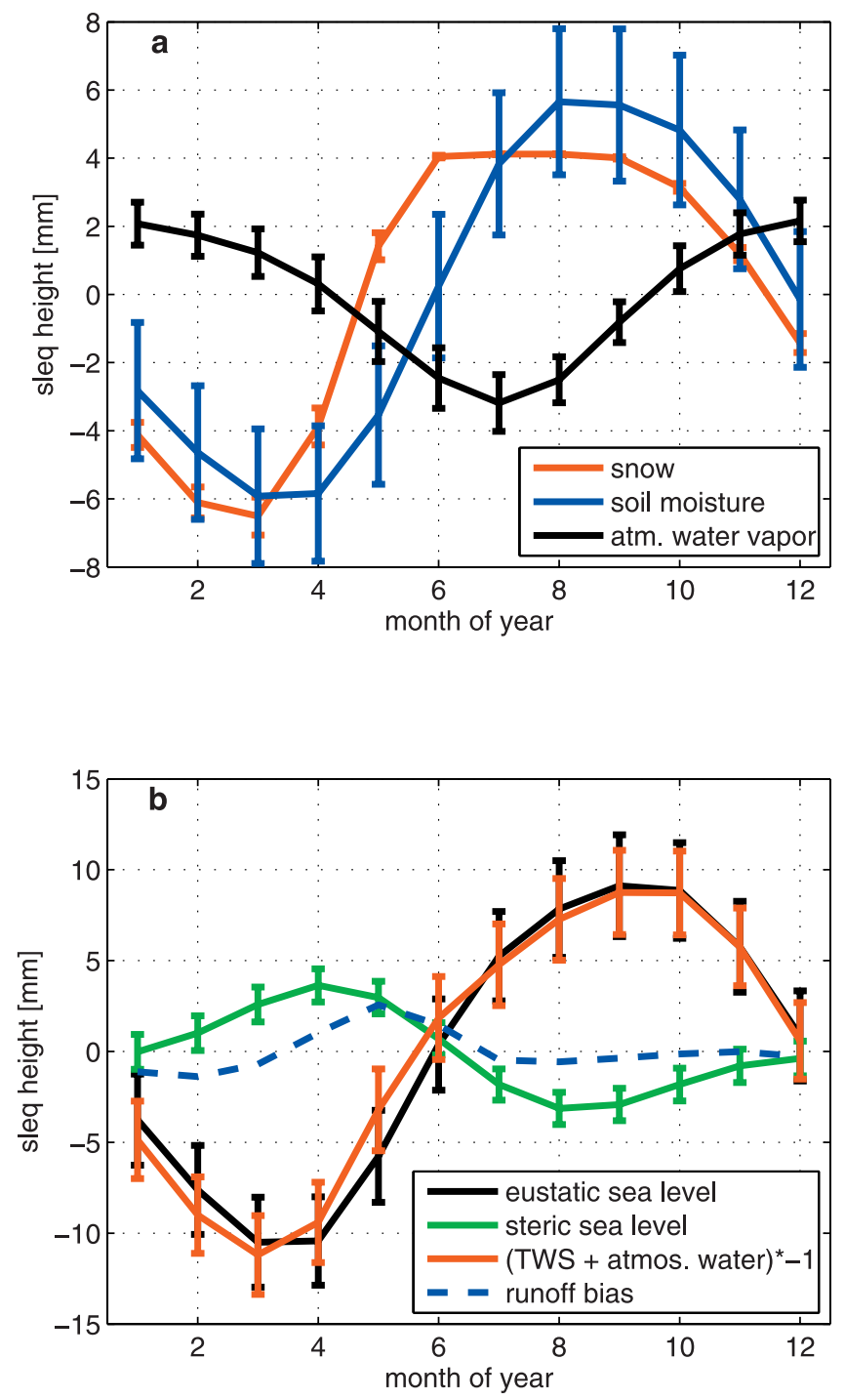

Figure 2. ( $a$ and b) Global mean seasonal mass balance terms. In Figure 2a, atmospheric water vapor is the black curve, soil moisture is the blue curve, and snow is the red curve. In Figure 2b, steric sea level is the green curve, sum of seasonal atmospheric and terrestrial water storage terms are the red curve, eustatic sea level is the black curve, and difference between them (runoff bias) is the blue curve. In Figures $2 \mathrm{a}$ and $2 \mathrm{~b}$, the error bars are the monthly standard deviation. Units are mm of equivalent sea level height.

introduces serial correlation into the time series, which would make any statistical test less stringent [Trenberth, 1984]. The number of degrees of freedom is reduced to the effective number of independent observations, $N_{\text {eff }}$, defined as [Trenberth, 1984]

$$
N_{\text {eff }}=N \frac{\Delta t}{T_{0}} .
$$

Here, $\Delta t$ is the sampling interval, and $T_{0}$ denotes the time between effectively independent observations. There are various possibilities (and difficulties) in estimating $T_{0}$ [von Storch and Zwiers, 1999], but for large numbers of observations, $N$, and under the assumption of a process with a red spectrum, we can approximate $T_{0}$ by

$$
T_{0}=\frac{1+\alpha}{1-\alpha}
$$

where $\alpha$ is the product of the lag 1 autocorrelation values of the regression time series [Trenberth, 1984]. Intuitively, $T_{0}$ can be thought of as an integral timescale representing physical memory in the system [von Storch and Zwiers, 1999].

\section{Results}

\subsection{ENSO Signals in the Global Mean Sea Level and Water Budget}

[12] For the assessment of ENSO-related variability in Earth's water mass budget, we need to subtract the seasonal cycle from all relevant terms. The monthly climatology of the sea level and water budget terms (Figure 2), computed from 200 years of ECHAM5/MPI-OM simulated data, is consistent with published observational or other simulated estimates within the standard deviation determined from our simulation (Table 1). However, the mean seasonal eustatic GMSL contribution in ECHAM5/MPI-OM is above the observed range, while the seasonal steric GMSL contribution is below. Since the eustatic and steric GMSL variations are about $180^{\circ}$ out-of phase, the total seasonal GMSL variation (steric plus eustatic GMSL) is therefore considerably above the observed range $(7.5 \mathrm{~mm}$ compared to $5.0 \mathrm{~mm}$; Table 1). Note, though, that ice sheets are not dynamically coupled in our simulation, so their contribution to eustatic GMSL variations is not included. Cazenave et al. [2000] estimated a seasonal sea level contribution from Antarctica of about $3 \mathrm{~mm}$ (maximum in December), and a seasonal sea level contribution from Greenland of about $0.6 \mathrm{~mm}$ (maximum in July), but error bars on both estimates are rather large. The seasonal signal of steric GMSL is representative of the seasonal cycle of ocean heat content, which is basically confined to the ocean volume above the upper thermocline. In ECHAM5/MPI-OM, the seasonal cycle of ocean heat uptake and release is smaller than observed, and therefore the steric GMSL amplitude is also underestimated. This appears to be a typical shortcoming of climate models, which tend to have too little ocean heat storage variability on seasonal to decadal timescales [Gregory et al., 2004]. Consistent with the overestimated eustatic GMSL variations, the seasonal atmospheric and terrestrial water storage amplitudes in ECHAM5/MPI-OM also tend to be larger than published estimates (Table 1). The contributions of soil moisture and snow to seasonal TWS variations are about equal in ECHAM5/MPI-OM, which is quite different from estimates published by Cazenave et al. [2000]. Recent estimates [e.g., Syed et al. 2008], however, suggest a more equal contribution of soil moisture and snow to seasonal TWS variations. Soil moisture and snow mass are probably the least well observed water storage quantities, and are often crudely approximated in models, so error bars of these estimates should be rather large. As explained in section 2.1, not all terrestrial water storage terms necessary to close the water storage budget are available as model output. This runoff bias has a maximum seasonal sea level contribution 
Table 1. Seasonal Amplitude, Standard Deviation, and Phase of the Maximum of the Reservoir Storage and Sea Level Terms in ECHAM5/MPI-OM, Compared to Published Estimates Based on Observations and Other Models ${ }^{\mathrm{a}}$

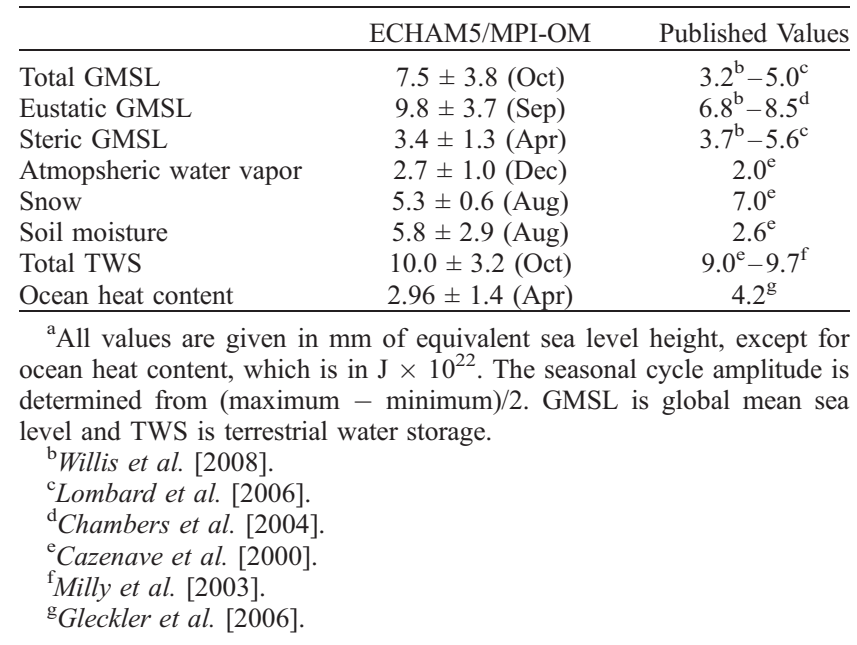

of about $2.5 \mathrm{~mm}$ in May (Figure 2); during this time, precipitation or melting snow enters runoff directly without being stored in the soil or as snow. Note also that in comparing seasonal cycle amplitudes between model simulations and observations, a considerable source of uncertainty comes from the use of different averaging periods; in general, averaging periods in observation-based estimates are much shorter than in our simulations. In light of the discussed uncertainties and model limitations, the comparison in Table 1 shows that the seasonal GMSL budget in ECHAM5/MPI-OM is well captured.

[13] After subtracting the monthly climatology (Figure 2), we proceed with analyzing whether nonseasonal sea level, water storage and loading anomalies are correlated with ENSO. All time series have been filtered as described in section 2.3. In terms of overall monthly anomalies, eustatic sea level and soil moisture have the largest amplitudes, and also the largest temporal variability (Table 2 and Figures $3 \mathrm{a}$ and $3 \mathrm{c}$ ). A correlation of $c=-0.95$ indicates that the largest fraction of nonseasonal water storage anomalies is exchanged between the oceans and the soils. Snow and atmospheric water vapor anomalies contribute considerably less to eustatic sea level (Figures $3 \mathrm{~b}$ and $3 \mathrm{~d}$ ). As in the calculation of the seasonal cycle, we need to account for the monthly anomalies of the runoff bias to close the mass budget. The amplitude of this term is generally small, with larger values occurring concurrently with strong changes in soil moisture and snow storage. Correcting the sum of soil moisture and snow storage with the runoff bias does not alter the amplitude and phasing of the total terrestrial storage significantly: the correlation between corrected and uncorrected terrestrial water storage is $c=0.93$.

[14] For all storage terms in Figure 3, we perform the linear regression on the Nino3 index as described in section 2.3. From the total of 2400 time steps, only between 33 to 157 are effectively independent, reducing the number of degrees of freedom significantly (Table 2). These estimates are rather conservative and make the significance test quite stringent, but it prevents incorrect rejections of the null hypothesis that there is no regression relation between the storage terms and ENSO. For eustatic sea level, the regression on Nino3 around lag zero is marginally significant with about $0.5 \mathrm{~mm} / \sigma_{N 3}$, but the explained variance is very low at only $7 \%$ (Figures $4 \mathrm{a}$ and 4b). In contrast, significant correlation exists between global atmospheric water storage and ENSO. At a lag of three months, the regression coefficient of global atmospheric water storage on ENSO is maximum with $0.6 \mathrm{~mm} / \sigma_{N 3}$, and $80 \%$ of the variance can be explained by Nino3. Significant correlation also exists when the atmospheric water storage leads ENSO by 15 months, but the explained variance drops to $28 \%$ (Figures $4 \mathrm{c}$ and $4 \mathrm{~d}$ ). The regression of total soil moisture storage on ENSO is maximum at about $-0.9 \mathrm{~mm} /$ $\sigma_{N 3}$, when the soil moisture storage lags ENSO by five months. Although statistically significant, ENSO explains only a maximum of about $26 \%$ of the total soil moisture storage variance. Snow storage does not have a significant regression at any lag (Figures $4 \mathrm{e}-4 \mathrm{~h}$ ). The total terrestrial storage, including soil moisture, snow and the runoff bias, leads to a maximum regression of almost $-1.1 \mathrm{~mm} / \sigma_{N 3}$ (explained variance: $25 \%$ ), lagging ENSO by four months (Figures $3 \mathrm{i}$ and $3 \mathrm{j}$ ). The results of the regression analysis can be nicely illustrated in a single plot (Figure 5). Since the water budget is mainly balanced between terrestrial storage and eustatic sea level, the two reservoirs anomalies project onto each other with a slope of nearly minus one. However, El Niño and La Niña events do not separate along the regression line, but instead above and below, demonstrating that atmospheric water storage as the remaining reservoir is tightly correlated with ENSO, whereas the water distribution between the ocean and continents is not.

[15] So far, we have considered contributions to the eustatic sea level signal. The GMSL is also influenced by steric sea level anomalies, which have no bearing on the global ocean mass. We have computed the steric anomalies here from the fully time-dependent density changes, as opposed to a climatological background salinity distribution (which is often done in observations due to sparse salinity measurements). Steric GMSL is closely related to ocean

Table 2. Maximum Nonseasonal Amplitude, Standard Deviation, Memory Timescale, and Effective Number of Independent Observations (Equation (6)) of Monthly Anomalies of GMSL and Loading Contributions ${ }^{\mathrm{a}}$

\begin{tabular}{lcccc}
\hline & Amplitude $^{\mathrm{b}}$ & $\sigma^{\mathrm{b}}$ & $T_{0}{ }^{\mathrm{c}}$ & $N_{\text {eff }}{ }^{\mathrm{c}}$ \\
\hline Total GMSL & 7.5 & 2.2 & 53 & 45 \\
Eustatic GMSL & 5.4 & 1.7 & 42 & 57 \\
Steric GMSL & 3.0 & 0.9 & 72 & 33 \\
Atmospheric water vapor & 2.2 & 0.6 & 49 & 49 \\
Soil moisture & 5.0 & 1.6 & 49 & 49 \\
Snow & 0.9 & 0.2 & 20 & 120 \\
Total TWS & 7.2 & 2.0 & 46 & 52 \\
Wet atmospheric ocean loading & 1.6 & 0.5 & 51 & 46 \\
Dry atmospheric ocean loading & 3.6 & 1.2 & 15 & 157 \\
\hline
\end{tabular}

${ }^{a} \mathrm{~A}$ high-pass filter with a cutoff period of 11 years and a 5-month running mean have been applied to all time series. GMSL is global mean sea level and TWS is terrestrial water storage.

${ }^{\mathrm{b}}$ Values given in $\mathrm{mm}$ of equivalent GMSL.

${ }^{\mathrm{c}}$ Values in months.

${ }^{\mathrm{d}}$ Corrected for runoff bias. 

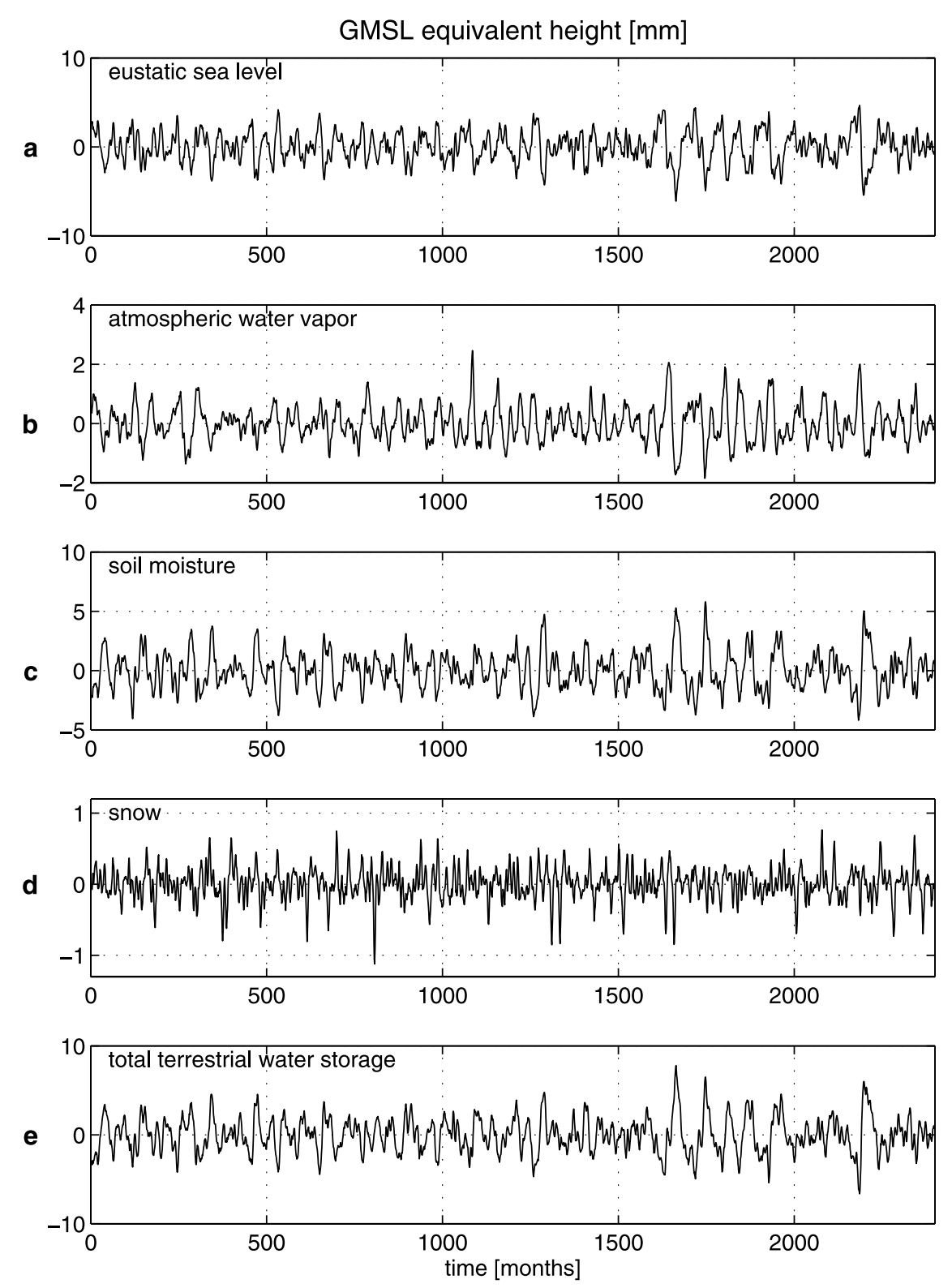

Figure 3. Nonseasonal monthly anomalies of (a) eustatic sea level, (b) atmospheric water vapor, (c) soil moisture, (d) snow, and (e) total terrestrial water storage (corrected with the "runoff bias"). A high-pass filter with a cutoff period of 11 years and a 5-month running mean have been applied to all time series. Units are $\mathrm{mm}$ of equivalent sea level height.

heat content (OHC). Here, the correlation between monthly anomalies of $\mathrm{OHC}$ and steric GMSL is 0.95 . The regression of the high-pass filtered global $\mathrm{OHC}$ on $\mathrm{Nino} 3$ shows a significant signal of about $2.7 \times 10^{21} \mathrm{~J} / \sigma_{N 3}$ when $\mathrm{OHC}$ leads Nino3 by four months (Figures 6a and 6d). Steric GMSL has a maximum regression of about $0.65 \mathrm{~mm} / \sigma_{N 3}$ when it leads Nino3 by one month, with an explained variance of nearly $46 \%$ (Figures $6 \mathrm{~b}$ and $6 \mathrm{e}$; for the unfiltered anomalies, this value drops below $8 \%$ ). The fact that the maximum $\mathrm{OHC}$ regression leads the steric GMSL regression by about 4 months could be related to the nonlinear equation of state, but as the relative lag difference is within individual regression error bars, this assertion is somewhat speculative. The regression of the total (eustatic plus steric) GMSL variations on Nino3 yields a significant maximum response of about $1 \mathrm{~mm} / \sigma$ at zero lag. However, the variance of the total GMSL anomalies explained with ENSO is only $18 \%$ (Figures 6c and 6f).

[16] In contrast to steric sea level, mean atmospheric loading changes over the oceans $\overline{\left(\overline{\eta_{a}^{\prime}}\right.}$ in equation (3)) have no bearing on GMSL, but they do affect the mean mass load at the sea floor. Therefore, and in anticipation of the discussion of the degree-two geopotential signals in section 3.3, we briefly examine the relation of $\overline{\eta_{a}^{\prime}}$ to ENSO. Additionally, we split the term $\overline{\eta_{a}^{\prime}}$ into its dry and wet air load contribution $\left(\overline{\eta_{a}^{\prime}}\right.$ dry and $\overline{\eta_{a}^{\prime}}$ wet, respectively). We find that $\overline{\eta_{a}^{\prime}}$ dry can be a factor two larger than $\overline{\eta_{a}^{\prime}}{ }^{\text {wet }}$, and $\overline{\eta_{a}^{\prime}}{ }^{\text {dry }}$ contains considerably more high-frequency variability compared to $\overline{\eta_{a}^{\prime}}$ wet (Table 2). The regression of $\overline{\eta_{a}^{\prime}}{ }^{\text {wet }}$ on Nino3 is very similar to that of the global atmospheric water vapor content (Figure 7b, compare 
to Figure 4c). The explained variance of ${\overline{\eta_{a}^{\prime}}}^{\text {wet }}$ with ENSO is nearly $80 \%$, so we can conclude that most of the ENSOrelated global atmospheric water vapor anomalies are located over the oceans, which increase ocean bottom pressure in a globally uniform way under the IB assumption. However, the sum of the combined ocean loading response $\left(\overline{\eta_{a}^{\prime}}{ }^{\text {wet }}+\overline{\eta_{a}^{\prime}}{ }^{\text {dry }}\right)$ is less prominent because $\overline{\eta_{a}^{\prime}}$ dry and $\overline{\eta_{a}^{\prime}}$ wet tend to cancel each other (Figure 7c). The regression of the full atmospheric loading on Nino3 is still statistically significant at lags around \pm 10 months, but the explained variance is less than $10 \%$ (Figure 7f).

\subsection{ENSO Signals in the Surface Loading Patterns}

[17] So far, we have considered the spatially integrated loading anomalies of the individual reservoirs and their relation to eustatic GMSL, without resolving the spatial pattern. In this section, we analyze the geographic patterns of all simulated loading anomalies, as these patterns determine the degree-two geoid anomalies (equation (4)). We also take dynamic ocean and atmospheric mass redistribution into account, because they affect ocean bottom and surface pressures, respectively, but without changing the total mass of either one.

\subsubsection{Ocean Loading Pattern}

[18] While the eustatic sea level anomalies represent a uniform ocean bottom pressure anomaly, dynamic ocean mass redistribution leads to spatially nonuniform bottom pressure changes. We estimate the dynamic bottom pressure anomalies by subtracting the simulated steric sea level fields from the dynamic sea level fields (equation (3), but excluding $\overline{\eta_{a}^{\prime}}$ and $\overline{\eta_{Q}^{\prime}}$ ). The sea level pattern related to ENSO is well established [Nerem et al., 1999]: during El Niño, sea level rises in the eastern and central Pacific, and falls in the western Pacific (Figure 8a). Since altimetric sea level is well correlated with heat content in the tropical Pacific region [e.g., Willis et al., 2004], this pattern mainly reflects the deepening and shoaling of the thermocline in the eastern/central and western Pacific, respectively. Accordingly, the simulated sea level signal is almost entirely explained by thermosteric anomalies (Figure 8c); halosteric sea level anomalies often have an opposing sign, but are much smaller in amplitude (Figure 8d). Only the western tropical Pacific features a noticeable halosteric anomaly of $2 \mathrm{~mm} / \sigma_{N 3}$, but this is still a factor 3 less than the corresponding thermosteric anomaly in this region.

[19] The pattern of bottom pressure anomalies is very different from the sea level anomalies, which suggests that ENSO-related ocean variability is baroclinic rather than barotropic (Figures $8 \mathrm{a}-8 \mathrm{e}$ ). The largest bottom pressure signals appear on the shallow shelf areas (Figure 8e; we focus on the pattern lagging Nino3 by 4 months, because this is the dominant large-scale signal). On the Sunda shelf and on the shelves along Northern Australia, bottom pressure changes are in opposite phase to ENSO, with regressions up to $-50 \mathrm{~mm} / \sigma_{N 3}$; on the Bering Sea shelf, bottom pressure changes are in-phase with ENSO, with a maximum amplitude of $20 \mathrm{~mm} / \sigma_{N 3}$. In the northwest Pacific basin we find a small negative bottom pressure regression coefficient. Prominent signals are also visible northwest of Drake passage and southwest of Australia. While these regions are associated with large seasonal bottom pressure variability of $20 \mathrm{~mm}$ (RMS) [Condi and Wunsch, 2004], a smaller fraction of this signal could arise from ENSO variability. An intriguing aspect of Figure 8e is the large-scale pattern of positive bottom pressure correlations in the Pacific, and negative correlations in the Atlantic and Indian Ocean. It appears that the mass balance between these ocean basins is influenced by ENSO, although the amplitude of this largescale bottom pressure pattern is generally very small, with a maximum of only $2 \mathrm{~mm}$. In their estimate of the ocean's seasonally varying geoid contribution, Wahr et al. [1998] found a qualitatively similar large-scale pattern, but they did not discuss a causative physical mechanism. The associated necessary mass transport between the basins is very small (about 4 orders of magnitude less than the typical Drake Passage transport [Wahr et al., 1998]). Our result here suggests that at least part of this interbasin mass transfer is related to ENSO processes (or, more generally, to tropical Pacific variability).

[20] Over most areas, ENSO explains at the most 5\% of the nonseasonal bottom pressure variance. Along the tropical Pacific, the explained variance increases up to $30 \%$, but the regression coefficients are small at $0-4 \mathrm{~mm} / \sigma_{N 3}$; on the Sunda and north Australian shelves, the explained variance increases up to $55-60 \%$, and the bottom pressure signals reach relatively high amplitudes of $40-50 \mathrm{~mm} / \sigma_{N 3}$. In previous work, we have shown that steric sea level changes arising from deeper ocean layers involve a horizontal mass redistribution within the ocean, and can therefore contribute to regional mass load (and therefore geoid) changes, contrary to what is sometimes stated [Landerer et al., 2007b]. In particular, this mechanism can account for the high-amplitude bottom pressure signal on the shallow shelf areas.

\subsubsection{Atmospheric Loading Pattern}

[21] The general pattern of the atmospheric surface pressure variations associated with ENSO is well established [e.g., Trenberth and Caron, 2000]: during El Niño episodes, lower than normal pressure is observed over the eastern tropical Pacific and higher than normal pressure is found over Indonesia and northern Australia; during La Niña, the pattern reverses. This pressure pattern is associated with the anomalous wind pattern, and ECHAM5/MPI-OM reproduces it well (Figures 9a and 9b). The regression of the dipole in the Southern Ocean and the northwest Pacific anomaly on ENSO yields large amplitudes, but the explained variance in these regions is below $5 \%$.

[22] Since we showed in section 3.1 that the global mean water vapor content is strongly dependent on ENSO, we estimate its contribution to the total surface pressure separately. The ENSO-related anomaly pattern of this wet atmospheric pressure closely resembles the shifts of precipitation patterns observed during El Niño, with positive anomalies in the eastern and central Pacific, and negative anomalies in the western part and over Indonesia and Australia (Figure 9c). Over the central tropical Pacific, the regression of vertically integrated water vapor reaches values up to $8 \mathrm{~mm} / \sigma_{N 3}$, with explained variance over $60 \%$ (Figure $9 \mathrm{~d}$ ). Negative regression values over Indonesia and Australia are generally smaller, and explained variances are below 5\%.

[23] Over the central and eastern part of the tropical Pacific, the wet atmospheric pressure anomalies partly compensate the dry atmospheric pressure anomalies. However the general pattern and sign of the anomalous dry 
Regression [mm eqs/h/ $\sigma(\mathrm{N} 3)]$
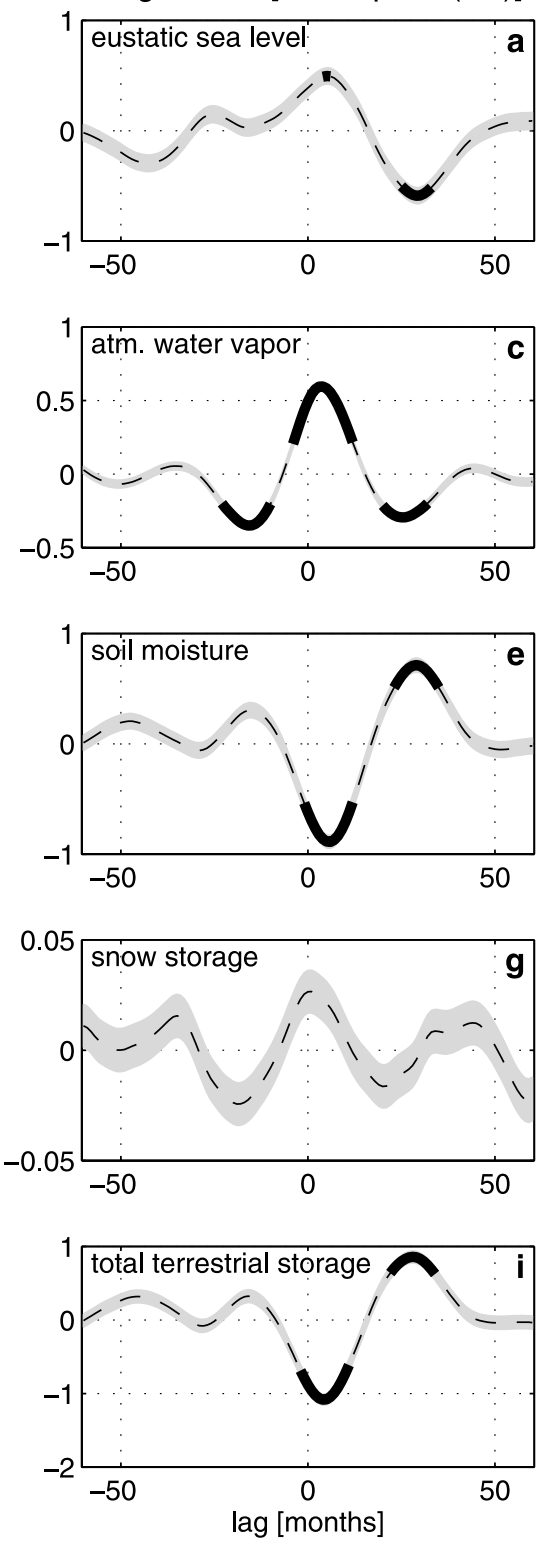

Explained variance [\%]
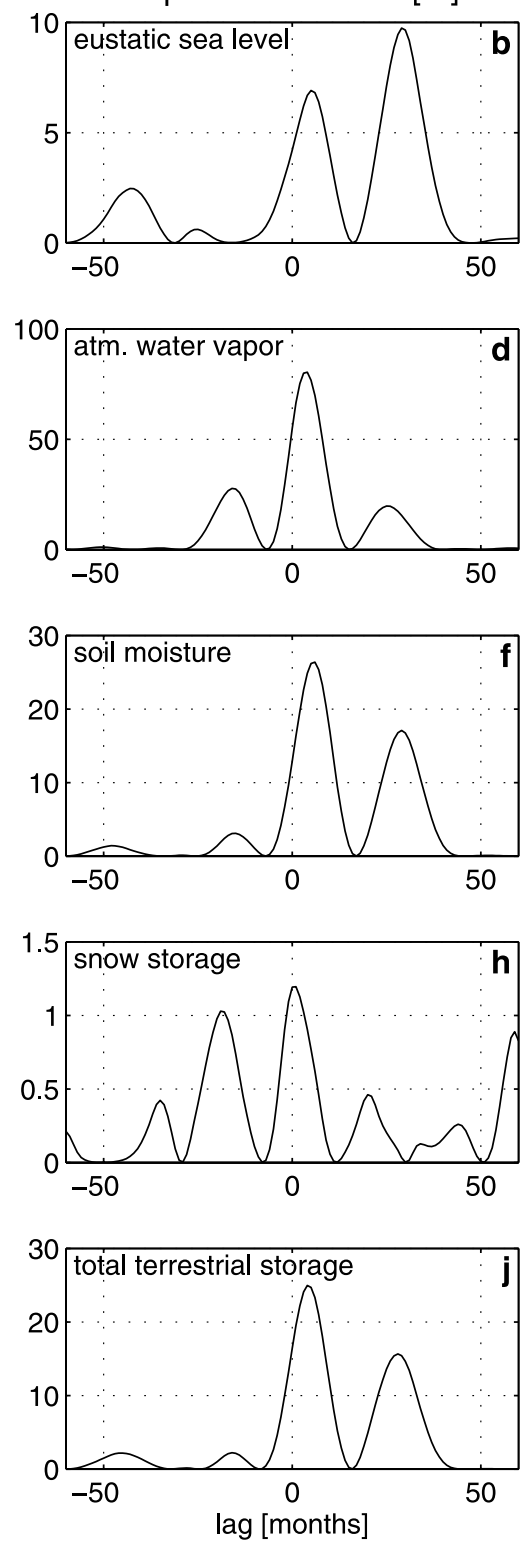

Figure 4. (left) Lagged regression coefficients and (right) explained variance of (a and b) eustatic sea level, (c and d) atmospheric water vapor, (e and f) soil moisture, (g and h) snow, and (i and j) total terrestrial water storage (soil moisture + snow + runoff bias). Solid black lines in the Figure 4 (left) indicate that the regression coefficient is significant at the $95 \%$ level; the formal uncertainty of the regression coefficient is indicated by the shading.

surface pressure pattern is not changed. Note that atmospheric surface pressure variations over the oceans cause a spatially uniform mass load anomaly at the ocean bottom under the IB assumption (see section 2.1), and degree-two geopotential signals from this part of atmospheric variability must be accounted for with equation (5). Therefore, the effective atmospheric ocean loading is obtained from the regression coefficients in Figure 7, rather than from the regression coefficients in Figure 9.

\subsubsection{Terrestrial Loading Pattern}

[24] In contrast to the pattern of atmospheric surface pressure, the large-scale pattern of terrestrial water storage anomalies due to ENSO is poorly known; recent satellite gravity measurements cover too short a time span to give the full range of nonseasonal storage variability. In our model simulation, we find that terrestrial water storage shows large-scale ENSO-related variability, with local regression amplitudes between -50 to $+30 \mathrm{~mm} / \sigma_{N 3}$. Compared to an estimated seasonal water storage amplitude of nearly $400 \mathrm{~mm}$ water equivalent height in the Amazon basin [Schmidt et al., 2006], our results indicate that ENSO modulated water storage variability can be substantial.

[25] The Amazon Basin, Australia, southeast Asia and parts of southern Africa have less soil water in phase with Nino3, while North America, southeastern South America and parts of western Africa have more soil water in phase 


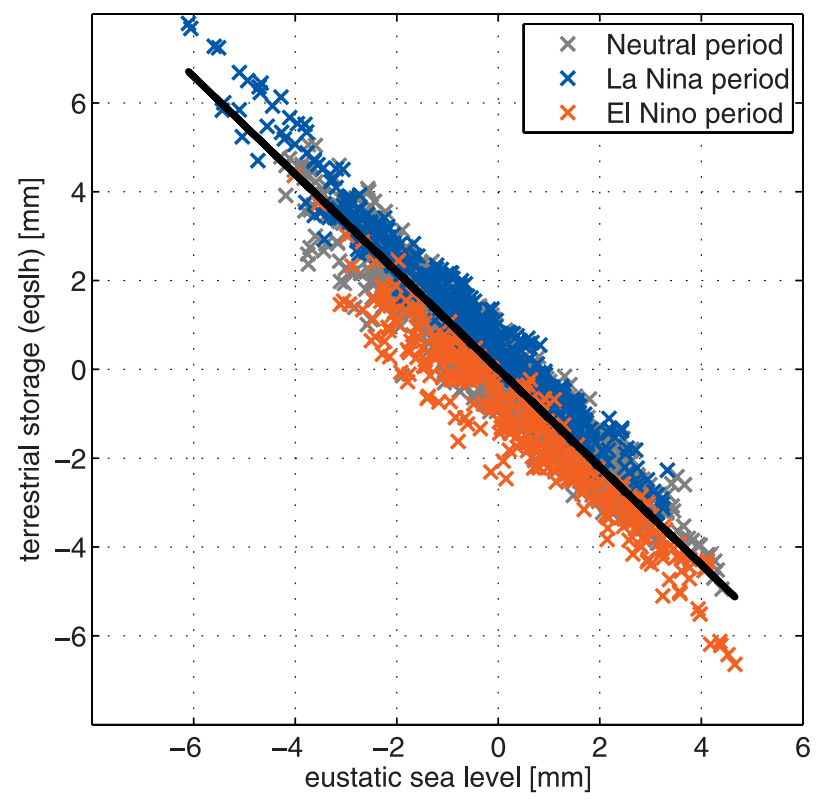

Figure 5. Scatterplot of nonseasonal eustatic sea level versus sea level equivalent total terrestrial water storage. Blue crosses indicate cold La Niña phases, and red crosses indicate warm El Niño phases (see also Figure 1). A highpass filter with a cutoff period of 11 years and a 5-month running mean have been applied.

with Nino3 (Figure 10). This large-scale pattern is roughly consistent with the typical pattern of precipitation anomalies expected during the warm and cold ENSO phases. The explained variance of the monthly soil moisture anomalies for these regions is between $10-20 \%$, in parts of the Amazon basin the explained variance reaches up to $30-$ $35 \%$. The regression pattern of snow is much more geographically confined and the explained variance does not exceed $10 \%$ (not shown), indicating that snow variability is mostly driven by processes other than ENSO. Note, again, that snow variability over continental ice sheets is not included here.

[26] In principle we also have to account for the pattern of the runoff bias that was discussed in section 3.1. Although we only know its globally integrated value, we can make some inference about its geographical distribution because it is related to the runoff field, but its grid point storage anomalies should be considerably smaller than those of the total runoff field. We find that the regression of the total runoff field on Nino3 has small regression amplitudes (mostly well below $2 \mathrm{~mm} / \sigma_{N 3}$ ), and the explained variance of $2-3 \%$ in most areas is negligible (not shown). Therefore, the runoff bias should not contribute significantly to ENSOrelated local terrestrial water storage, and we neglect this term in what follows.

\subsection{ENSO Signals in the Degree-Two Stokes Coefficients}

[27] Surface mass load variations lead to changes in Earth's geopotential field, which can be expressed in spherical harmonics, the so-called Stokes coefficients. The degree-two Stokes coefficients are particularly interesting as they are related to Earth rotation parameters [Barnes et al., 1983; Chen et al., 2005]. We compute the coefficients $C_{21}$, $S_{21}$ and $C_{20}$ from the surface mass load anomalies as
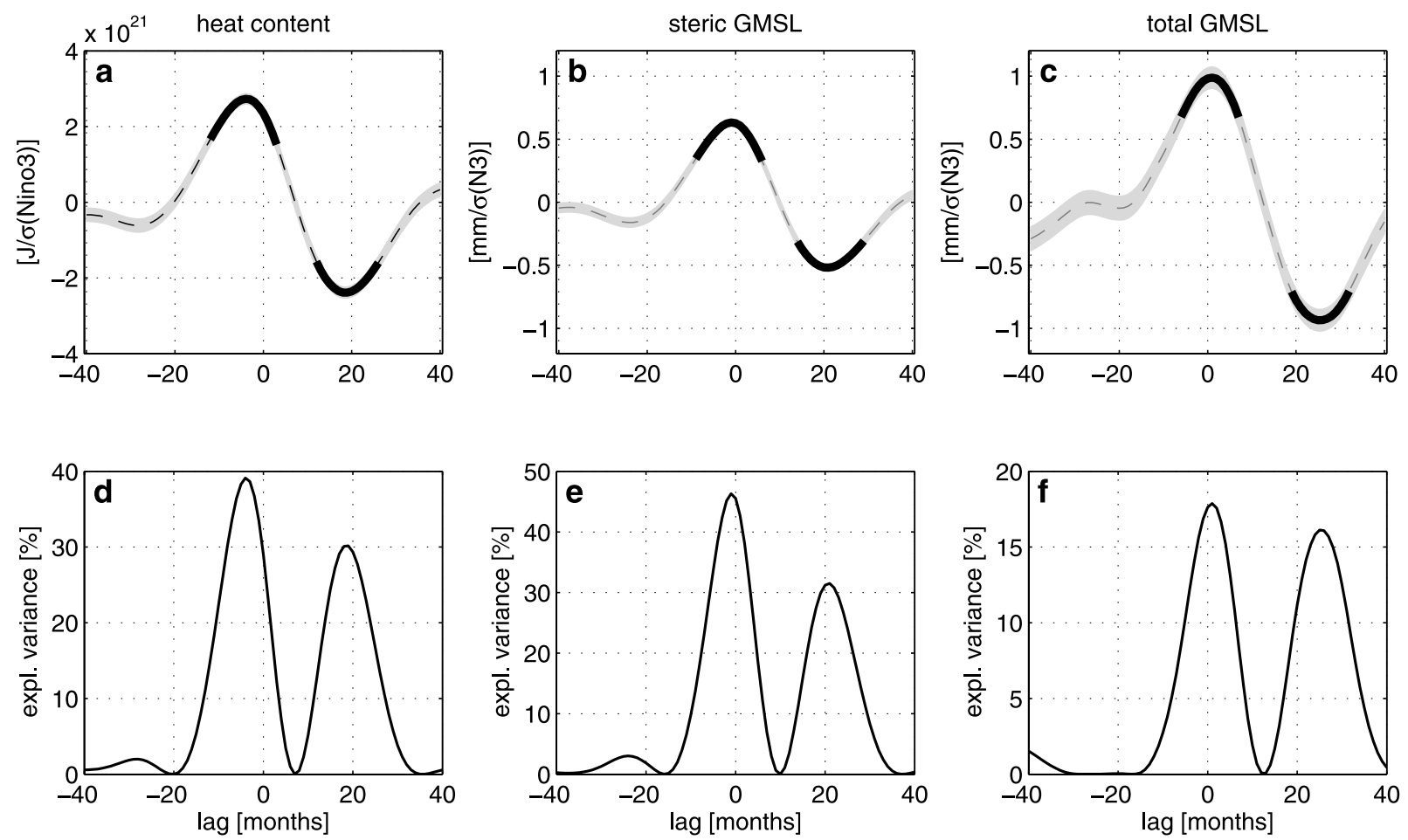

Figure 6. (top) Lagged regression coefficients and (bottom) explained variance of (a and d) ocean heat content, (b and e) steric sea level, and (c and f) total sea level (eustatic + steric). The solid black line indicates that the regression is significant at the $95 \%$ level. 

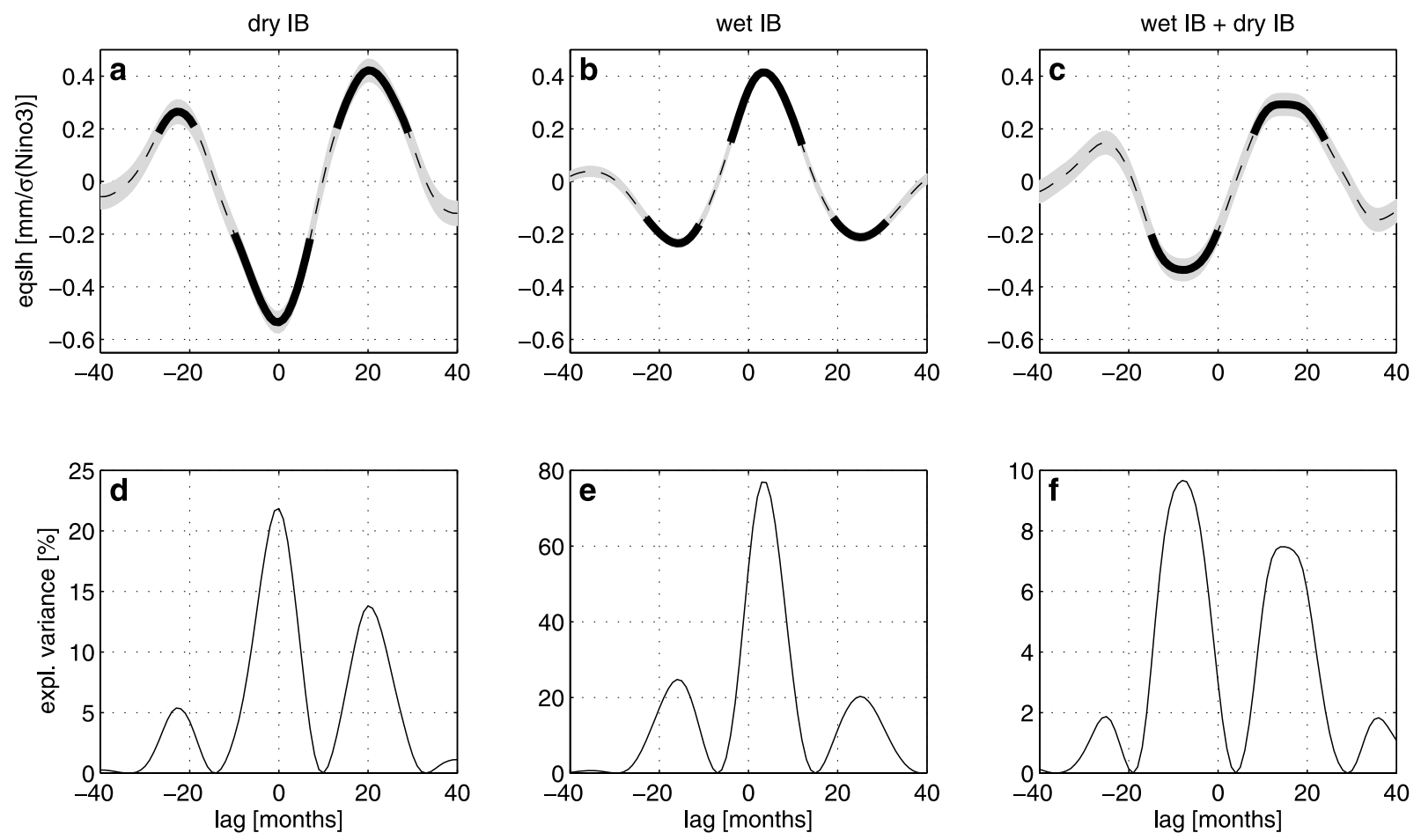

Figure 7. (top) Lagged regression coefficients and (bottom) explained variance of (a and d) dry IB, (b and e) wet IB, and (c and f) total IB (wet plus dry IB) signals. The solid black line indicates that the regression is significant at the $95 \%$ level.

detailed in section 2.2. All time series have been filtered as described in section 2.3. Table 3 summarizes the nonseasonal temporal standard deviation of all loading terms that contribute to the combined degree-two Stokes coefficients; similar variability in the nonseasonal coefficients was found by Chen et al. [2005]. In our simulation, the largest contribution to $C_{20}$ comes from atmospheric loading, whereas $S_{21}$ and $C_{21}$ are mainly influenced by terrestrial water storage and dynamic ocean bottom pressure fluctuations. Loading signals from eustatic sea level and atmospheric IB changes contribute comparatively little to the degree-two Stokes anomalies. Since the total atmospheric signal is much larger than that because of IB loading over the oceans, most of the variability of the total atmospheric degree-two Stokes signal must be excited over land. Also, there is only minor compensation between the degree-two coefficients from wet atmospheric IB loading and eustatic sea level, as the larger fraction of the eustatic sea level anomaly is balanced with water storage on the continents (see Figure 5). For the combined signal with all individual contributions taken into account, the single largest anomalies do not occur concurrently in the different degree-two coefficients. A few strong ENSO events appear to have a coherent response in the time series of $S_{21}$ and $C_{20}$, but less so in $C_{21}$ (not shown). For a quantitative assessment of ENSO-related variability in the degree-two geoid coefficients, we calculate their linear regression on ENSO. We do this for each subsystem contribution separately (oceans, atmosphere and continents), and also for the combined Earth system response (Figure 11).

\subsubsection{Regression of $C_{21}$}

[28] The largest contribution to $C_{21}$ comes from soil moisture anomalies, but the regression is only marginally significant. Atmospheric loading, ocean bottom pressure, and snow all significantly contribute to $C_{21}$ at the $95 \%$ level near zero lag, but since their contribution is about $180^{\circ}$ out of phase with that from soil moisture, the ENSO signal in the combined $\mathrm{C}_{21}$ coefficient is very weak and statistically not significant; the maximum explained variance for nonseasonal $\mathrm{C}_{21}$ anomalies is extremely low at less than $1.5 \%$ (Figure 11g).

\subsubsection{Regression of $S_{21}$}

[29] The largest contribution to $S_{21}$ comes from dynamic ocean bottom pressure, and this signal is significant for lags between -5 to +12 months (Figure $11 \mathrm{~b}$, red line). The contribution from soil moisture is about $30 \%$ smaller, lags the ocean bottom pressure signal by about 5 months, and is significant only between lags of +3 to +12 months (Figure 11b, blue line). Regressions for atmospheric and snow loading are formally significant, but comparatively small in amplitude. Since the individual contributions are largely in phase near zero lag, the regression of the combined $\mathrm{S}_{21}$ coefficient is maximum at about $1.35 \times$ $10^{-11} / \sigma_{N 3}$, lagging Nino3 by 4 months and explaining about $30 \%$ of the variance (Figure $11 \mathrm{~h}$ ).

\subsubsection{Regression of $\boldsymbol{C}_{20}$}

[30] The largest contribution to $\mathrm{C}_{20}$ comes from soil moisture, with significant regression lags between -2 to +15 months (Figure 11c, blue line). The maximum atmospheric loading contribution is about $65 \%$ smaller, and $90^{\circ}$ out of phase (Figure 11c, black line). Note that atmospheric 

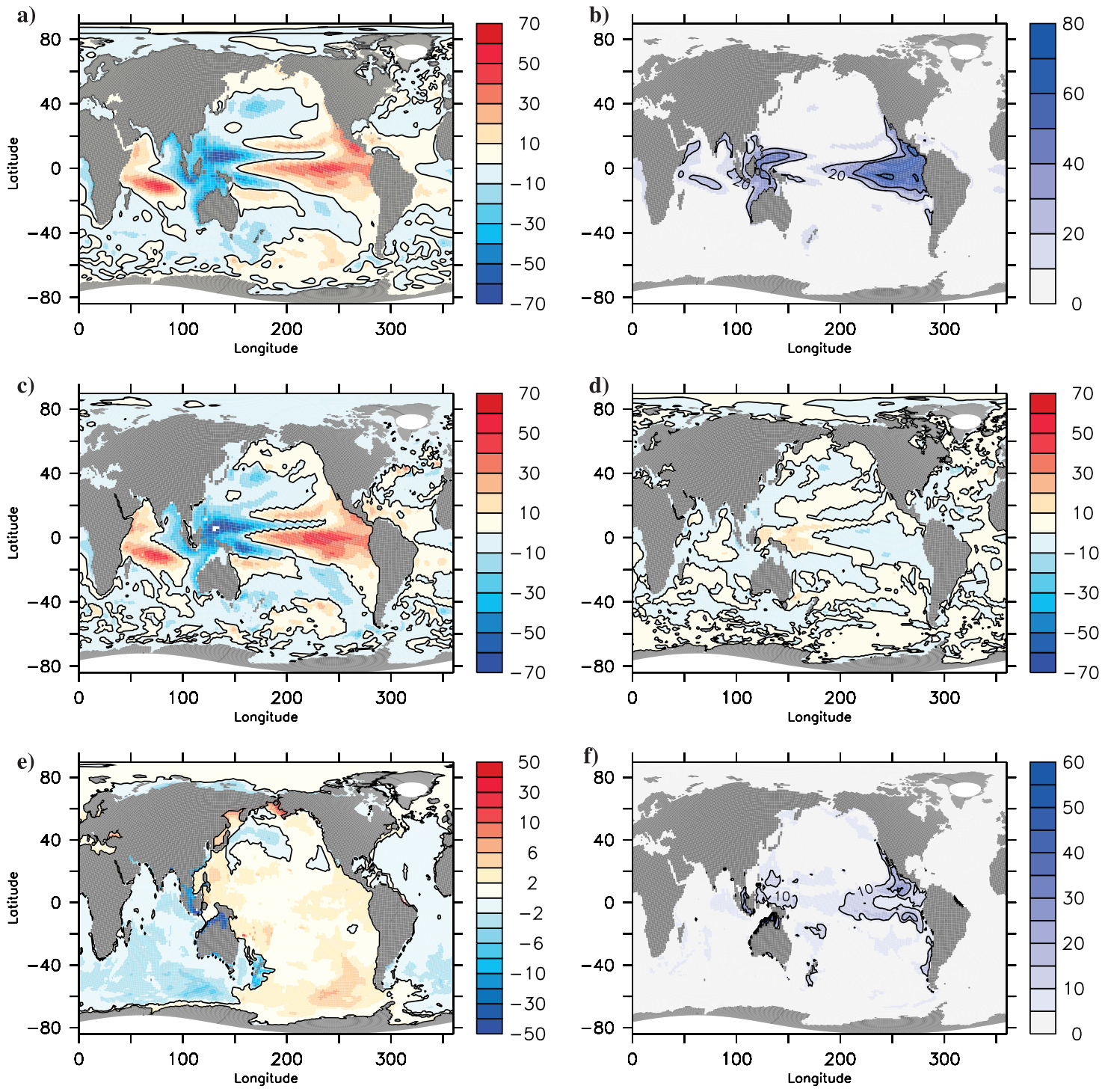

Figure 8. ( $\mathrm{a}$ and $\mathrm{b}$ ) Regression $\left(\mathrm{mm} / \sigma_{N 3}\right)$ on the Nino3 index and explained variance (in percent) of nonseasonal dynamic sea level $(\mathrm{lag}=0)$, regression of nonseasonal $(\mathrm{c})$ thermosteric and $(\mathrm{d})$ halosteric sea level, and regression of (e) nonseasonal dynamic bottom pressure (Nino3 leading by 4 months) and (f) explained variance (in percent). Note that the color scale in Figure 7e is not linear.

loading contributes most to temporal nonseasonal variability in $\mathrm{C}_{20}$ (Table 3 ), but much of it is apparently not related to ENSO. Degree-two Stokes signals from dynamic ocean bottom pressure and snow storage contribute comparatively little to the total $\mathrm{C}_{20}$ signal, and are not significant (Figure 11c). Therefore, the total $\mathrm{C}_{20}$ signal is largely determined by the amplitude and phase of the soil moisture anomalies. Lagging Nino 3 by 2 months, the regression coefficient is maximum at $1.1 \times 10^{-11} / \sigma_{N 3}$, but the maximum explained variance is rather low at $9.5 \%$ (Figure $11 \mathrm{i}$ ).

\section{Summary and Discussion}

[31] The first issue we address in this paper is whether ENSO can be systematically associated with a global steric or eustatic GMSL anomaly, and how the hydrologic mass balance between oceans, atmosphere and continents is achieved. Using simulations from an unconstrained coupled climate model with consistent water exchange between the subsystems, we find a small positive regression of steric GMSL anomalies on ENSO with $0.65 \mathrm{~mm} / \sigma_{N 3}$, leading ENSO by 1 month. Even for strong ENSO events, such as during 1997/1998, we would therefore not expect a net global steric sea level change of more than $2-3 \mathrm{~mm}$. This is in contrast to the study of Nerem et al. [1999], but consistent with the study of Willis et al. [2004]. Note, however, that our regression coefficients for steric GMSL could be too conservative since our model underestimates seasonal ocean heat uptake.

[32] An important result of this study is that the simulated eustatic changes dominate monthly to interannual GMSL, but they are not strongly correlated with ENSO variability (Figure 5). Our inferred large contribution of eustatic GMSL variations on these relatively short timescales is consistent with the most recent observations of GMSL 

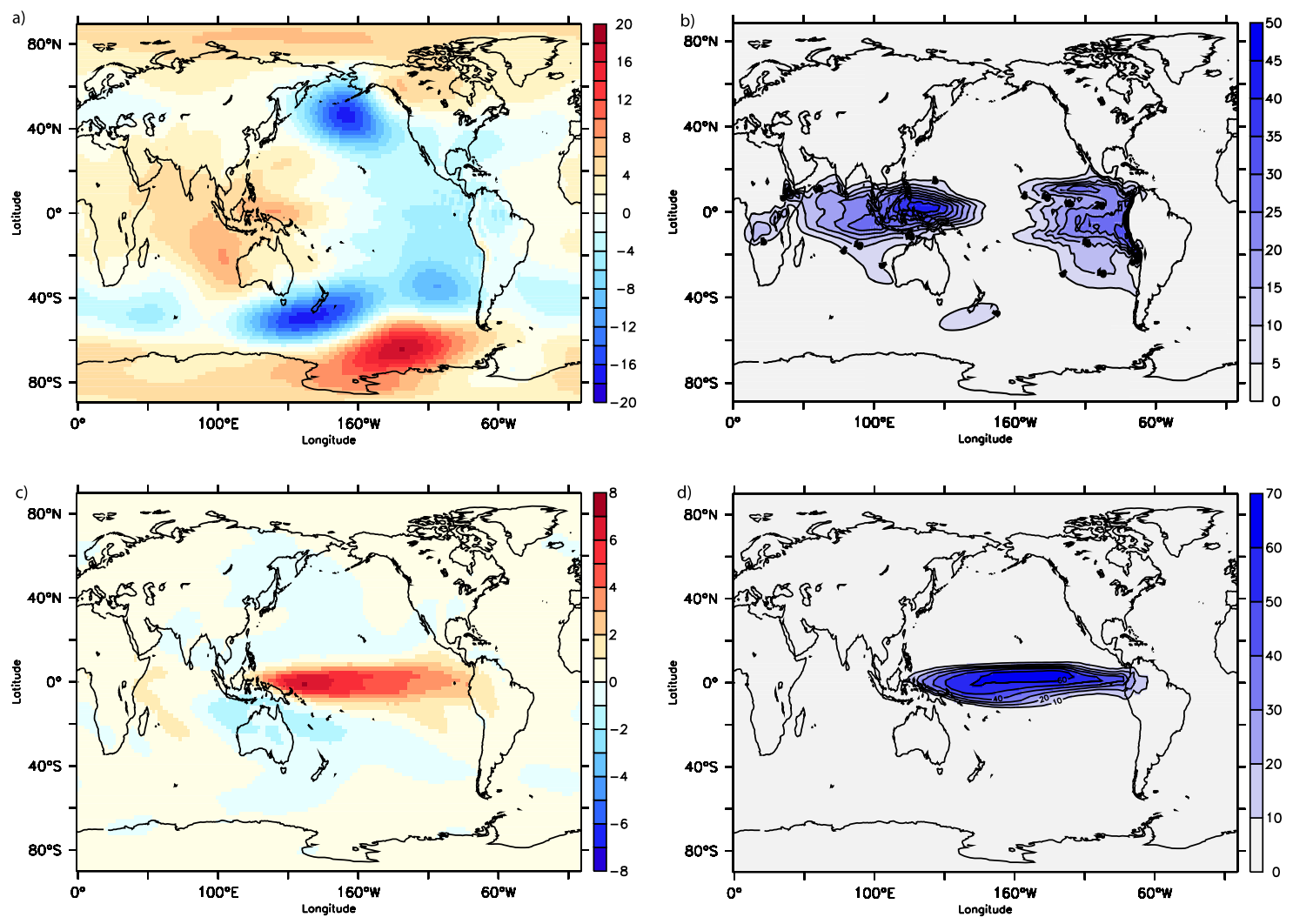

Figure 9. Regression $\left(\mathrm{mm} / \sigma_{N 3}\right)$ on the Nino3 index of (a) nonseasonal total atmospheric surface pressure anomalies (lag $=0)$ and $(\mathrm{b})$ explained variance (in percent) and regression on the Nino3 index of (c) nonseasonal wet atmospheric surface pressure anomalies only (lag $=0$ ) and $(d)$ explained variance (in percent).

variations from satellite altimetry, gravity measurements, and hydrographic floats [Willis et al., 2008]. Regressing the total (steric plus eustatic) GMSL variations on ENSO yields a significant signal of about $1 \mathrm{~mm} / \sigma$ at zero lag, but the explained variance is rather low at $18 \%$. This implies that observed interannual GMSL changes cannot be attributed straightforwardly to ENSO by using a standard ENSO index, which in turn complicates the attribution of such GMSL variations. While it is well established that ENSO has profound impacts on the hydrological cycle [Trenberth et al., 2002], our results indicate that the relative distribution of the precipitation anomalies over land or over the oceans varies for different ENSO events. A moderate $25 \%$ of the total terrestrial water storage variance can be explained with ENSO, with a regression coefficient of about $-1.1 \mathrm{~mm} / \sigma_{N 3}$.

[33] The atmosphere as the third water storage subsystem can hold only a very limited amount of water, but up to $80 \%$ of the variance of total atmospheric water vapor can be explained with ENSO. With a maximum regression of $0.6 \mathrm{~mm} / \sigma_{N 3}$ lagging the Nino3 index by 3 months, the role
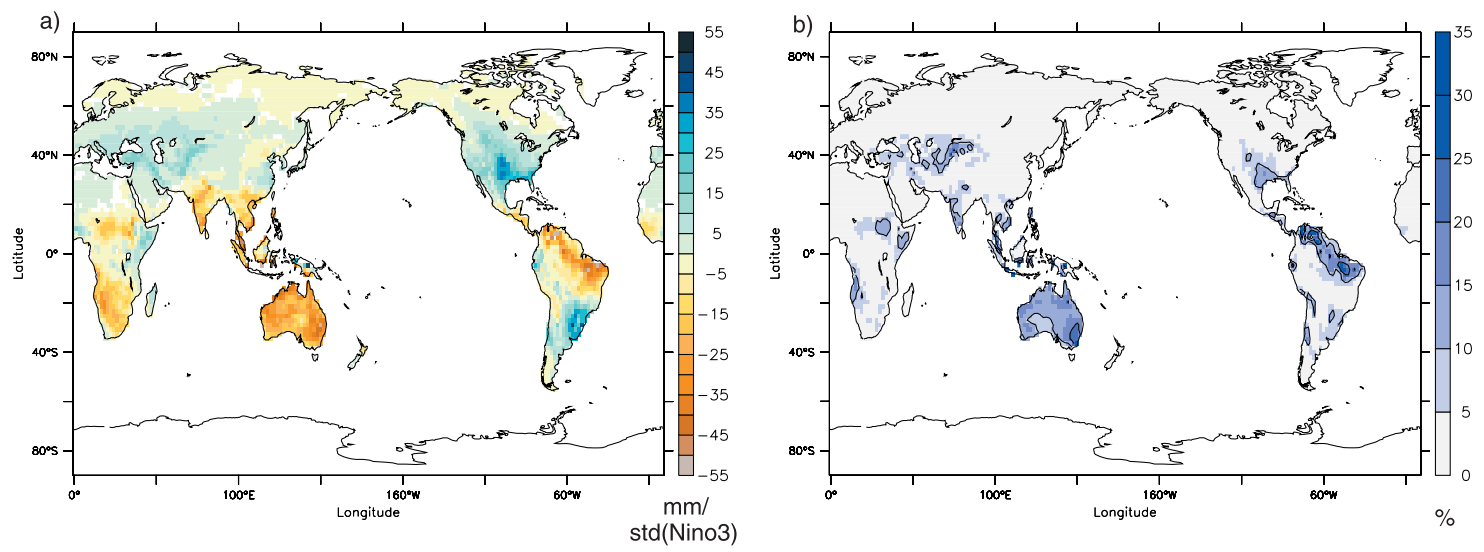

Figure 10. (a) Regression of nonseasonal soil moisture anomalies on the Nino3 index (Nino3 leading by 4 months). Units are $\mathrm{mm} / \sigma_{N 3}$. (b) Explained variance (in percent). 
Table 3. Standard Deviation of the Nonseasonal Degree-Two Stokes Coefficients From the Combined Individual Surface Loading and Uniform Sea Level Terms ${ }^{\mathrm{a}}$

\begin{tabular}{lccc}
\hline \multicolumn{1}{c}{ Source } & $\sigma\left(C_{21}\right)^{\mathrm{b}}$ & $\sigma\left(S_{21}\right)^{\mathrm{b}}$ & $\sigma\left(C_{20}\right)^{\mathrm{b}}$ \\
\hline Combined loading & 1.36 & 2.35 & 3.45 \\
Dynamic ocean bottom pressure & 0.80 & 1.28 & 1.47 \\
Total atmospheric loading & 1.29 & 3.81 & 3.00 \\
Terrestrial storage & 0.89 & 1.25 & 1.40 \\
Eustatic GMSL & 0.08 & 0.14 & 0.07 \\
Wet atmospheric ocean loading & 0.02 & 0.04 & 0.02 \\
Dry atmospheric ocean loading & 0.06 & 0.10 & 0.05 \\
\hline
\end{tabular}

${ }^{\mathrm{a}} \mathrm{A}$ high-pass filter with a cutoff period of 11 years and a 5-month running mean have been applied to all time series.

${ }^{b}$ Values are in $\times 10^{-11}$

of the atmosphere is mainly that of a mediator between the terrestrial and oceanic subsystem. Most of the atmospheric water vapor anomaly is located over the tropical Pacific. As mentioned in section 2.1, our model simulation cannot account for eustatic GMSL variations that arise from the growing or melting of land ice sheets. In order to assess the possible impact of this limitation on ENSO-related eustatic GMSL, we have regressed the patterns of surface temperature and precipitation anomalies onto the simulated Nino3 index. Since we do not find significant correlations over the Greenland and Antarctic ice sheets, we do not expect the cryosphere to influence our results.

[34] The second purpose of this paper is to identify the simulated geographical patterns of ENSO-related hydrologic mass load anomalies and to quantify their impact on the degree-two geopotential coefficients $C_{21}, S_{21}$ and $C_{20}$. We find statistically significant correlations to ENSO for $S_{21}$ (explained variance up to $30 \%$ ) and $C_{20}$ (explained variance up to $9.5 \%$ ), but not for $C_{21}$ (explained variance less than $1.5 \%$ ). In terms of contributions from the individual subsystems, anomalies in dynamic ocean bottom pressure and soil moisture storage are the most important contributors to ENSO-related anomalies in $S_{21}$; anomalies in soil moisture storage are also the main contributor in $C_{20}$. This result is
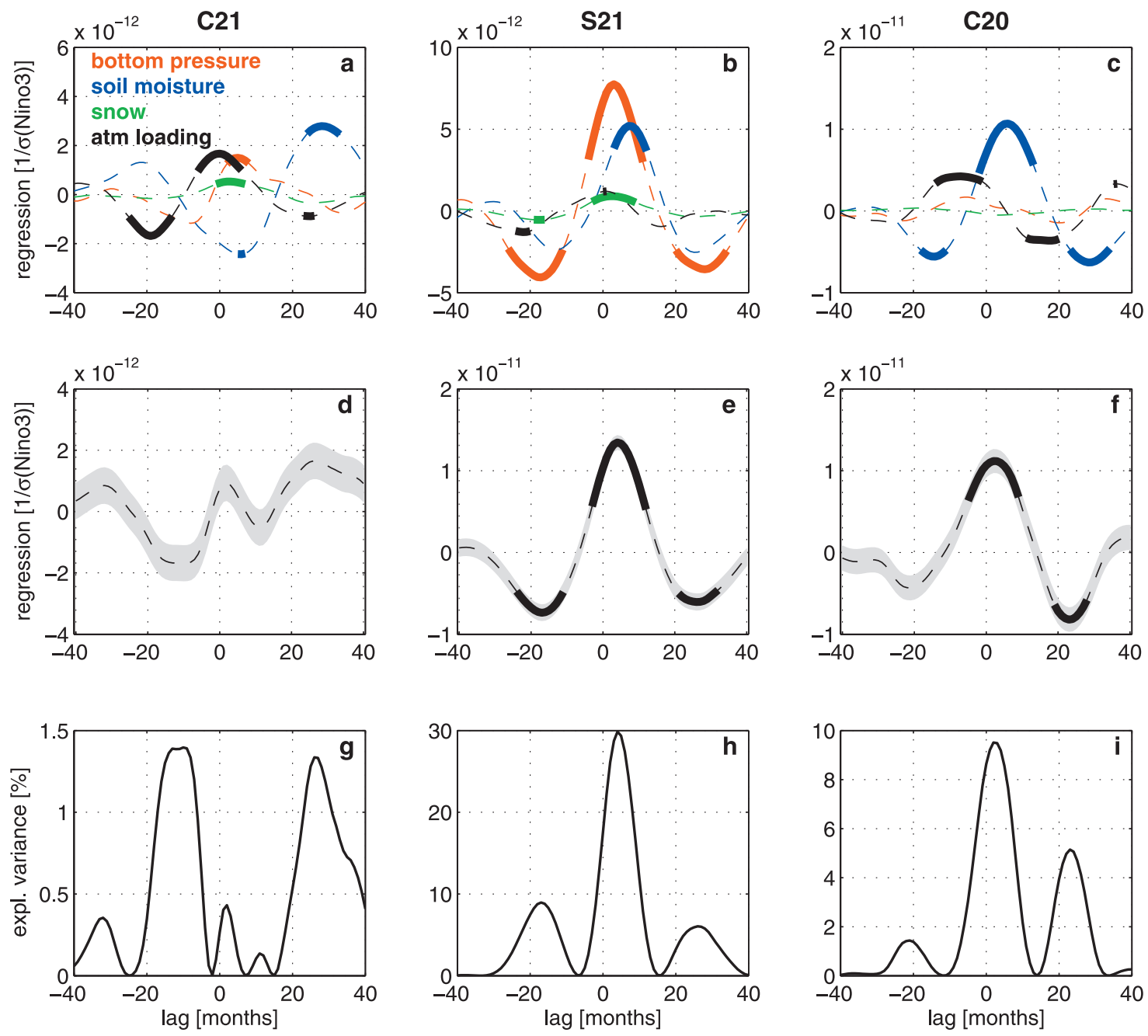

Figure 11. Regression on Nino3 $(\mathrm{a}-\mathrm{c})$ of the individual loading contributions to the nonseasonal Stokes coefficients, $(\mathrm{d}-\mathrm{f})$ of the total Stokes coefficients, and $(\mathrm{g}-\mathrm{i})$ explained variance (in percent) of the total nonseasonal Stokes coefficients: (left) $\mathrm{C}_{21}$, (middle) $\mathrm{S}_{21}$, (right) and $\mathrm{C}_{20}$. The legend in Figure 11a applies to Figures $11 \mathrm{~b}$ and $11 \mathrm{c}$ as well. Ocean bottom pressure does not include eustatic sea level and IB. In Figures 11d-11f, the solid black lines indicate regressions significant at the $95 \%$ level. 
consistent with Cheng and Tapley [2004], who also highlighted the importance of interannual soil moisture anomalies for $C_{20}$ qualitatively, but we can now quantify this contribution. As discussed in the introduction, the dynamic links between large-scale climate modes and near-surface mass shifts that led to the observed $C_{20}$ anomaly during 1997/ 1998 have not been fully resolved. Dynamic mass redistribution in the oceans, as simulated here, can lead to $C_{20}$ anomalies similar to those observed during 1997/1998. However, the simulated ocean signal is not significantly correlated to ENSO. This can, of course, also be a shortcoming of the ECHAM5/MPI-OM model. For the subpolar North Pacific gyre region, others (Y. T. Song and V. Zlotnicki, Subpolar ocean-bottom-pressure oscillation and its links to the tropical ENSO, submitted to International Journal of Remote Sensing, 2007.) have found ocean bottom pressure signals that are well correlated to ENSO, whereas the variance explained with ENSO of our signals (Figure 8 ) are below 5\%. Whether this discrepancy has any bearing on latitudinal ocean mass redistribution and therefore on C20 variations is presently not clear and should be subject of further research. Overall, the large-scale pattern of ENSO-related surface loading anomalies has the highest amplitudes over the continents. Here, the explained variance reaches $30-35 \%$ over regions where ENSO typically influences precipitation. The large-scale surface loading anomalies from the atmosphere and oceans have a considerably smaller amplitude and might be difficult to detect with current satellite observational systems (e.g., GRACE).

[35] A prominent anomaly in $C_{20}$ was observed concurrently with the strong ENSO event of 1997/1998. In analyzing the surface mass redistribution associated with this anomaly, Dickey et al. [2002] found a significant contribution from dynamic ocean mass redistribution. In contrast, we do not find a significant impact of ENSOrelated oceanic mass redistribution on $C_{20}$ variations in our simulations. On the premise that the studies of Dickey et al. [2002] and our present one are correctly representing the examined processes, this discrepancy would have to interpreted such that climate modes other than ENSO (e.g., the Pacific Decadal Oscillation) caused the oceanic mass redistribution that lead to the observed $1997 / 1998 C_{20}$ anomaly. Moreover, our results show that the ENSO impact on terrestrial water storage, especially on soil moisture, has the potential to significantly affect $C_{20}$ (and also $S_{21}$ ). However, the regression amplitude of $C_{20}$ on ENSO from the coupled model simulation is too small to account for the magnitude of the $1997 / 1998 C_{20}$ event. Therefore, we cannot rule out other excitation sources, such as mass imbalances of the large Antarctic or Greenland ice sheets or solid Earth processes during 1997/1998.

\section{Conclusions}

[36] On the basis of simulations with a coupled Earth system model, we conclude the following:

[37] 1. Monthly to interannual variations of global mean sea level are dominated by eustatic rather than steric variations. However, these dominant eustatic variations are not strongly linked to ENSO variability in a linear fashion.

[38] 2. The simulated eustatic global mean sea level anomalies are mostly balanced with the terrestrial water storage. Therefore, the distribution between eustatic global mean sea level and terrestrial water storage is also not strongly linked to ENSO variability in a linear fashion.

[39] 3. Surface loading anomalies from ocean mass redistribution and soil moisture both contribute to ENSO-related anomalies in the $S_{21}$ and $C_{20}$ geoid coefficients, whereas soil moisture loading is effectively the only source for ENSOrelated anomalies in the $C_{20}$ coefficient.

[40] 4. Atmospheric loading anomalies are of secondorder importance for ENSO-related degree-two geoid coefficient variations from, because these loading anomalies are mostly located over the oceans, and are therefore effectively damped under the inverted barometer effect.

[41] Acknowledgments. We would like to thank Steve Nerem and an anonymous reviewer for their constructive comments, which helped to clarify our results and improve the presentation. We also thank Erich Roeckner, Wolfgang Müller, Stefan Hagemann, and Joachim Segschneider for discussions during manuscript preparation. This work was supported by the Max Planck Society and the International Max Planck Research School on Earth System Modelling. The computer simulations were performed at the DKRZ (Deutsches Klimarechenzentrum) in Hamburg, Germany.

\section{References}

Barnes, R. T. H., R. Hide, A. A. White, and C. A. Wilson (1983), Atmospheric angular momentum fluctuations, length-of-day changes and polar motion, Proc. R. Soc. London Ser. A, 387(1792), 31-73.

Cazenave, A., and R. S. Nerem (2004), Present-day sea level change: Observations and causes, Rev. Geophys., 42(3), RG3001, doi:10.1029/ 2003RG000139.

Cazenave, A., F. Remy, K. Dominh, and H. Douville (2000), Global ocean mass variation, continental hydrology and the mass balance of Antarctica Ice Sheet at seasonal time scale, Geophys. Res. Lett., 27(22), 3755-3758.

Chambers, D. P., C. A. Mehlhaff, T. J. Urban, D. Fujii, and R. S. Nerem (2002), Low-frequency variations in global men sea level: 1950-2000, J. Geophys. Res., 107(C4), 3026, doi:10.1029/2001JC001089.

Chambers, D. P., J. Wahr, and R. S. Nerem (2004), Preliminary observations of global ocean mass variations with GRACE, Geophys. Res. Lett. 31, L13310, doi:10.1029/2004GL020461.

Chen, J. L., C. R. Wilson, D. P. Chambers, R. S. Nerem, and B. D. Tapley (1998), Seasonal global water mass budget and mean sea level variations, Geophys. Res. Lett., 25(19), 3555-3558, doi:10.1029/98GL02754.

Chen, J. L., C. R. Wilson, and B. D. Tapley (2005), Interannual variability of low-degree gravitational change, 1980-2002, J. Geod., 78, doi:10.1007/s00190-004-0417-y.

Cheng, M., and B. D. Tapley (2004), Variations in the Earth's oblatness during the past 28 years, J. Geophys. Res., 109, B09402, doi:10.1029/ 2004JB003028.

Church, J., J. M. Gregory, P. Huybrechts, M. Kuhn, K. Lambeck, M. T. Nhuan, D. Qin, and P. L. Woodworth (2001), Changes in sea level, in Climate Change 2001: The Scientific Basis, edited by J. T. Houghton et al., pp. 639-693, Cambridge Univ. Press, Cambridge, U. K.

Condi, F., and C. Wunsch (2004), Measuring gravity field variability, the geoid, ocean bottom pressure fluctuations, and their dynamical implications, J. Geophys. Res., 109, C02013, doi:10.1029/2002JC001727.

Cox, C. M., and B. F. Chao (2002), Detection of large-scale mass redistributions, Science, 297, 831-833, doi:10.1126/science.1072188.

Dickey, J. O., S. L. Marcus, O. de Viron, and I. Fukumori (2002), Recent Earth oblateness variations: Unraveling climate and postglacial rebound effects, Science, 298, 1975-1977, doi:10.1126/science.1077777.

Dümenil, L., and E. Todini (1992), A rainfall-runoff scheme for use in the Hamburg climate model, in Advances in Theoretical Hydrology, A Tribute to James Dooge, vol. 1, edited by J. O'Kane, pp. 129-157, Elsevier, Amsterdam.

Eubanks, T. M. (1993), Variations in the orientation of the Earth, in Contributions of Space Geodesy to Geodynamics-Earth Dynamics, Geodyn. Ser, vol. 24, edited by D. E. Smith and D. L. Turcotte, pp. 1-54, AGU, Washington, D. C.

Gill, A. E. (1982), Atmosphere-Ocean Dynamics, Int. Geophys. Ser, vol. 30 Academic, New York.

Gleckler, P. J., K. R. Sperber, and K. AchutaRao (2006), Annual cycle of global ocean heat content: Observed and simulated, J. Geophys. Res., 111, C06008, doi:10.1029/2005JC003223. 
Greatbatch, R. J. (1994), A note on the representation of steric sea level in models that conserve volume rather than mass, J. Geophys. Res., 99(C6), $12,767-12,771$

Gregory, J. M., H. T. Banks, P. A. Stott, J. A. Lowe, and M. D. Palmer (2004), Simulated and observed decadal variability in ocean heat content, Geophys. Res. Lett., 31(15), L15312, doi:10.1029/2004GL020258.

Guilyardi, E. (2006), El Niño mean state seasonal cycle interactions in a multi-model ensemble, J. Clim., 26, 329-348, doi:10.1007/s00382-0050084-6.

Hagemann, S. (2002), An improved land surface parameter dataset for global and regional climate models, MPI Rep. 336, Max Planck Inst. for Meteorol., Hamburg, Germany.

Hagemann, S., and L. Dümenil (1998), A parameterization of the lateral waterflow for the global scale, Clim. Dyn., 14(1), 17-31, doi:10.1007/ s003820050205.

Hagemann, S., K. Arpe, and E. Roeckner (2006), Evaluation of the hydrological cycle in the ECHAM5 model, J. Clim., 19(16), 3810-3827, doi:10.1175/JCLI3831.1.

Heiskanen, W. A., and H. Moritz (1967), Physical Geodesy, W. H. Freeman, New York.

Hughes, C. W., and V. N. Stepanov (2004), Ocean dynamics associated with rapid $\mathrm{J}_{2}$ fluctuations: Importance of circumpolar modes and identification of a coherent Arctic mode, J. Geophys. Res., 109, C06002, doi:10.1029/2003JC002176

Jungclaus, J. H., N. Keenlyside, M. Botzet, H. Haak, J.-J. Luo, M. Latif, J. Marotzke, U. Mikolajewicz, and E. Roeckner (2006), Ocean circulation and tropical variability in the coupled model ECHAM5/MPI-OM, J. Clim., 19(16), 3952-3972, doi:10.1175/JCLI3827.1.

Landerer, F. W., J. H. Jungclaus, and J. Marotzke (2007a), Regional dynamic and steric sea level change in response to the IPCC-A1B scenario, J. Phys. Oceanogr., 37(2), 296-312, doi:0.1175/JPO3013.1.

Landerer, F. W., J. H. Jungclaus, and J. Marotzke (2007b), Ocean bottom pressure changes lead to a decreasing length-of-day in a warming climate, Geophys. Res. Lett., 34, L06307, doi:10.1029/2006GL029106.

Lombard, A., D. Garcia, G. Ramillien, A. Cazenave, R. Biancale, J. M. Lemome, F. Flechtner, R. Schmidt, and M. Ishii (2006), Estimation of steric sea level variations from combined GRACE and Jason-1 data, Earth Planet. Sci. Lett., 254(1-2), 194-202, doi:10.1016/ j.eps1.2006.11.035.

Marsland, S. J., H. Haak, J. Jungclaus, M. Latif, and F. Röske (2003), The Max-Planck-Institute global ocean-sea ice model with orthogonal curvilinear coordinates, Ocean Modell., 5, 91-127.

McPhaden, M. J., S. E. Zebiak, and M. H. Glantz (2006), ENSO as an integrating concept in Earth science, Science, 314, 1740-1745.

Meehl, et al. (2007), Global climate projections, in Climate Change 2007. The Physical Science Basis, Contribution of Working Group I to the Fourth Assessment Report of the Intergovernmental Panel on Climate Change, edited by S. Solomon et al., pp. 19-91, Cambridge Univ. Press, Cambridge, U. K

Milly, P. C. D., A. Cazenave, and C. Gennero (2003), Contribution of climate-driven change in continental water storage to recent sea-level rise, Proc. Natl. Acad. Sci. U. S. A., 100(23), 13,158-13,161.

Munk, W. (2002), Twentieth century sea level: An enigma, Proc. Natl. Acad. Sci. U. S. A., 99, 6550-6555.

Nerem, R. S., D. P. Chambers, E. W. Leuliette, G. T. Mitchum, and B. S. Giese (1999), Variations in global mean sea level associated with the 1997-1998 ENSO event: Implications for measuring long term sea level change, Geophys. Res. Lett., 26, 3005-3008, doi:10.1029/ 1999GL002311.
Ponte, R. M. (1999), A preliminary model study of the large-scale seasonal cycle in bottom pressure over the global ocean, J. Geophys. Res., 104(C1), 1289-1300

Ponte, R. M., D. Salstein, and R. Rosen (1991), Sea level response to pressure forcing in a barotropic numerical model, J. Phys. Oceanogr. $21,1043-1057$

Roeckner, E., et al. (2003), The atmospheric general circulation model ECHAM5, part I: Model description, Tech. Rep. 349, Max Planck Inst. for Meteorol., Hamburg, Germany.

Schmidt, R., et al. (2006), Grace observations of changes in continental water storage, Global Planet. Change, 50, 112-126, doi:10.1016/ j.gloplacha.2004.11.018.

Soden, B. J. (2000), The sensitivity of the tropical hydrological cycle to ENSO, J. Clim., 13(3), 538-549, doi:10.1175/1520-0442(2000)013<0538.

Syed, T. H., J. S. Famiglietti, M. Rodell, J. Chen, and C. R. Wilson (2008), Analysis of terrestrial water storage changes from grace and gldas, Water Resour. Res., 44, W02433, doi:10.1029/2006WR005779.

Trenberth, K. E. (1984), Some effects of finite sample size and persistence in meteorological statistics. Part I: Autocorrelations, Mon. Weather Rev., $112,2359-2368$

Trenberth, K. E. (1997), The definition of El Niño, Bull. Am. Meteorol. Soc., 78, 2771-2777.

Trenberth, K. E., and J. M. Caron (2000), The Southern Oscillation revisited: Sea level pressures, surface temperatures, and precipitation, J. Clim. 13(24), 4358-4365.

Trenberth, K. E., G. W. Branstator, D. Karoly, A. Kumar, N.-C. Lau, and C. Ropelewski (1998), Progress during TOGA in understanding and modeling global teleconnections associated with tropical sea surface temperatures, J. Geophys. Res., 103, 14,291-14,324.

Trenberth, K. E., J. M. Caron, D. P. Stepaniak, and S. Worley (2002), The evolution of ENSO and global atmospheric surface temperatures, J. Geophys. Res., 107(D8), 4065, doi:10.1029/2000JD000298.

Trenberth, K. E., D. P. Stepaniak, and L. Smith (2005), Interannual variability of patterns of atmospheric mass distribution, J. Clim., 18, $2812-$ 2825

Vinogradova, N. T., R. M. Ponte, and D. Stammer (2007), Relation between sea level and bottom pressure and the vertical dependence of oceanic variability, Geophys. Res. Lett., 34, L03608, doi:10.1029/ 2006GL028588.

von Storch, H., and F. W. Zwiers (1999), Statistical Analysis in Climate Research, Cambridge Univ. Press, Cambridge, U. K.

Wahr, J., M. Molenaar, and F. Bryan (1998), Time variability of the Earth's gravity field: Hydrological and oeanic effects and their possible detection using GRACE, J. Geophys. Res., 103(B12), 30,205-30,229.

Willis, J. K., D. Roemmich, and B. Cornuelle (2004), Interannual variability in upper ocean heat content, temperature, and thermosteric expansion on global scales, J. Geophys. Res., 109, C12036, doi:10.1029/ 2003JC002260.

Willis, J. K., D. P. Chambers, and S. R. Nerem (2008), Assessing the globally averaged sea level budget on seasonal to interannual timescales, J. Geophys. Res., 113, C06015, doi:10.1029/2007JC004517.

Wunsch, C., and D. Stammer (1997), Atmospheric loading and the oceanic "inverted barometer" effect, Rev. Geophys., 35(1), 79-107.

J. H. Jungclaus and J. Marotzke, Max Planck Institute for Meteorology, Bundesstrasse 53, D-20146 Hamburg, Germany.

F. W. Landerer, Jet Propulsion Laboratory, California Institute of Technology, 4800 Oak Grove Drive, Pasadena, CA 91109, USA. (felix.landerer@zmaw.de) 